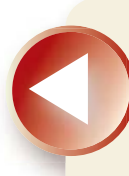
ANNUAL Further

Click here for quick links to Annual Reviews content online, including:

- Other articles in this volume

- Top cited articles

- Top downloaded articles

- Our comprehensive search

\section{Breaking the Barriers: Microbial Effector Molecules Subvert Plant Immunity}

\section{Vera Göhre and Silke Robatzek}

\author{
Max-Planck Institute for Plant Breeding Research, 50829 Cologne, Germany; \\ email: goehre@mpiz-koeln.mpg.de, robatzek@mpiz-koeln.mpg.de
}

Annu. Rev. Phytopathol. 2008. 46:189-215

First published online as a Review in Advance on April 18, 2008

The Annual Review of Phytopathology is online at phyto.annualreviews.org

This article's doi:

10.1146/annurev.phyto.46.120407.110050

Copyright (c) 2008 by Annual Reviews.

All rights reserved

0066-4286/08/0908-0189\$20.00

\section{Key Words}

basal resistance, PTI, PAMP/MAMP, PRR, virulence factor

\begin{abstract}
Adaptation to specialized environments allows microorganisms to inhabit an enormous variety of ecological niches. Growth inside plant tissues is a niche offering a constant nutrient supply, but to access this niche, plant defense mechanisms ranging from passive barriers to induced defense reactions have to be overcome. Pathogens have to break several, if not all, of these barriers. For this purpose, they secrete effector molecules into plant cells to interfere with individual defense responses. Plant defense is organized in multiple layers, and therefore the action of effectors likely follows this same order, leading to a hierarchy in effector orchestration. In this review we summarize the latest findings regarding the level at which effectors manipulate plant immunity. Particular attention is given to those effectors whose mechanism of action is known. Additionally, we compare methods to identify and characterize effector molecules.
\end{abstract}


T3SS: type-three secretion system

Effector: pathogendelivered molecules into host cells to suppress immune responses and promote pathogen proliferation

\section{PAMP/MAMP}

(pathogen-/microbeassociated molecular pattern): microbederived, highly conserved structures, recognized by PRRs to elicit immune responses, allow discrimination between self and nonself

\section{PRR (pattern recognition receptor): host- encoded receptors recognizing microbial patterns (PAMPs) with high specificity and affinity to trigger immune responses (PTI)}

LRR: leucine-rich repeat

RLK: receptor-like kinase

FLS2: Flagellin Sensing 2, receptor for flagellin

PTI (PAMPtriggered immunity): plant immune responses triggered by PAMPs, immediate, transient defense reactions

\section{INTRODUCTION}

Microorganisms live in highly diverse environments ranging from free-living organisms in soil or water to biofilms attached to hosts and even intercellular symbiotic or pathogenic host-dependent growth (61a). To adapt to the different conditions in each niche, microorganisms have evolved specialized strategies allowing them to live in roots, xylem or phloem vessels, leaves, flowers, or fruits. In addition to adaptation to a phytopathogenic lifestyle, pathogens must also have ways of spreading using, for example, physical means such as wind or water, given that their plant hosts are sessile organisms. The intensified use of monocultures in agriculture has caused the pathogenic lifestyle to become more pronounced (95).

Upon contact with a potential host plant, several pre-existing physical barriers such as the cuticle of leaves prevent entry into plant tissues (49), so that the pathogen has to rely on mainly natural openings, e.g., stomata and hydathodes or wound sites, to gain access. Following successful penetration, microoganisms need to persist within the apoplastic space. However, low pH (32) and plant-secreted degrading defense enzymes or antimicrobial compounds constitute the next barrier that the microbes have to overcome (49). Furthermore, plant cells are surrounded by a stable cell wall that cannot be penetrated by most microbes. Therefore, microbes, except for viruses and symbiotic bacteria, are confined to the apoplastic space for proliferation and have to devise means to access the cytosol, where they have to suppress defense responses and retrieve nutrients from the plant. Bacteria build a type-three secretion system (T3SS) that penetrates through the cell wall and plasma membrane to inject effector molecules into the cytoplasm to gain access to nutrients (53). Some fungi and oomycetes form appressoria that force penetration hyphae by turgor pressure through the cell wall. Subsequently, feeding structures (haustoria) are formed that are still surrounded by the plant plasma membrane. Effectors (Table 1) are secreted via exocytosis into the interfacial matrix, and some of them enter the plant cell and modify the cell to host the feeding structure (79).

On the one hand, plants can benefit from hosting microorganisms, e.g., in symbiosis with rhizobia or mycorrhiza, but on the other hand, microbial colonization by pathogens has detrimental effects. Therefore, in addition to preexisting physical and chemical barriers, plants express recognition systems and mount inducible immune responses that are triggered immediately after the first contact with nonself molecules and are reinforced by prolonged interaction with pathogens. PAMPs (pathogen-associated molecular patterns, also called MAMPs, microbe-associated molecular patterns, Table 1) are well-conserved molecular structures unique to microbes, that play an essential role in microbial lifestyle. Therefore, variation of these patterns to escape recognition is limited. During infection, PRRs (pattern recognition receptors, Table 1) recognize PAMPs and trigger defense responses in a cell-autonomous manner. Well-characterized examples for PRR/PAMP recognitions are the LRR-RLKs (leucine-rich repeat receptor-like kinase) FLS2 for bacterial flagellin (36), EFR for bacterial EF-Tu (117), CERK1 (75a) for fungal chitin and the receptor-like proteins (RLP) LeEix for fungal xylanase EIX (87), and CEBiP for fungal chitin (55). PRRs reside mostly in the plasma membrane. They stimulate signaling cascades involving $\mathrm{Ca}^{2+}$ fluxes and MAPKs (mitogen activated protein kinases), which lead to defense reactions. Production of ROS (reactive oxygen species) and medium alkalinization are harmful for the pathogen, deposition of callose in the cell wall perturbs penetration, while expression of antimicrobial products, e.g., PR (pathogenesis related) proteins and defensins further hinder infection $(96,110)$. If the pathogen cannot overcome these inducible defense mechanisms, efficient PTI [PAMP-triggered immunity, Table 1] is set off and pathogen proliferation in the apoplast is prevented. At this stage no or very few macroscopic disease symptoms occur, suggesting that PTI might underlie nonhost resistance (Table 1). 
Successful pathogens inject a range of effectors, which suppress defense responses at the level of perception, signaling, or defense action (37), thereby making host colonization possible.
However, these effector molecules can serve as signals for the plant to reinforce its defense. $\mathrm{R}$ (Resistance) proteins (Table 1) directly or indirectly (10) monitor the presence or actions

Table 1 Comparison of terms and concepts used to describe plant immunity ${ }^{1}$

PAMP/MAMP $=$ pathogen $/$ microbe-associated molecular pattern

PAMPs are structures or molecules that are conserved through whole classes of microbes including pathogenic and nonadapted microorganisms. They are targets of pattern recognition receptors of the eukaryotic innate immune system and allow perfect discrimination between self and nonself due to their specificity to microbes. Since PAMPs play an essential role for microbial life, evasion of recognition by adaptive evolution is unlikely or difficult to be achieved. In the past, PAMPs have been called "general elicitors."

\section{PRR = pattern recognition receptor}

PRRs are encoded by the host and mediate innate immune recognition. They are highly sensitive and specific recognition receptors for microbial patterns. Upon ligand perception, they stimulate signaling cascades that result in an array of typical defense responses. Plant plasma membrane spanning PRRs can be grouped into two classes: Receptor-like kinases (RLKs) carry a serine/threonine kinase domain, receptor-like proteins (RLPs) have a short cytoplasmic tail at the intracellular side. Their extracellular domains can contain leucine-rich repeats (LRRs) or LysM-motifs.

PTI = PAMP-triggered immunity

PAMP-triggered immunity (PTI) collectively encompasses all plant immune responses that are elicited upon challenge with PAMPs/MAMPs including those that only occur in the absence of effectors. PAMPs stimulate an immediate early and transient immune response contributing to different levels of plant immunity, e.g., in preinvasive defense by stomata closure or in postinvasive defense that includes ion fluxes, oxidative burst, activation of signaling cascades, changes in gene expression and focal accumulation of compounds with potential antimicrobial activity. PTI is in most cases sufficient to avoid microbial growth while ensuring host cell survival. Therefore, PTI is normally not associated with any macroscopic symptoms.

\section{Effector}

Effector molecules are important for pathogen virulence and promote penetration into host tissues, persistence inside the host, suppression of immune responses, access to nutrients, proliferation, and growth. Pathogens secrete effectors into intercellular spaces (apoplast) and into host cells. Bacteria are known to deliver effectors via their type-2- or type-3-secretion systems (T3SS); fungi and oomycetes release effectors via exocytosis. Also, effectors can be subject to horizontal gene transfer and adaptive evolution.

$\mathbf{R}$ protein (effector recognition receptor)

$\mathrm{R}$ proteins are encoded by specific hosts and have evolved to recognize effector molecules or their action. Upon recognition, R protein triggers a local hypersensitive response (HR) leading to programmed cell death (PCD). $\mathrm{R}$ proteins occur as plasma membrane-spanning RLKs and RLPs and intracellular receptors. Based on the N-terminal structure, the latter can be divided into CC- or TIR-NB-LRR type (CC, coiled-coil domain; TIR,

Toll-like-Interleukin-Receptor; NB, nucleotide binding domain).

ETI = effector-triggered immunity

Effector-triggered immunity (ETI) is elicited by host $\mathrm{R}$ proteins upon recognition of a cognate microbial effector (avirulence factor) or its action. Accumulating evidence points at ETI as a reactivation of PTI in an accelerated and potentiated manner. It occurs in two levels, weak and strong ETI. Weak ETI is usually not associated with any macroscopic symptoms, while strong ETI develops visible signs of HR. Classically, according to the gene-for-gene theory, strong ETI is referred to as incompatible interaction or is also called specific resistance. 


\begin{tabular}{|c|c|}
\hline Nonhost resistance & Basal resistance \\
\hline $\begin{array}{l}\text { The conceptual term of nonhost resistance describes } \\
\text { plant-microbe interactions at the macroscopic level. } \\
\text { Classically, plants undergo three types of interactions } \\
\text { with microbes: compatible, incompatible and non-host. } \\
\text { In a nonhost interaction, a normally virulent pathogen } \\
\text { for a particular host is not able to infect and grow in a } \\
\text { different type of host. At the molecular level, PTI } \\
\text { contributes to nonhost resistance, but also weak ETI } \\
\text { might be involved. }\end{array}$ & $\begin{array}{l}\text { In general, basal resistance (or basal defense) is } \\
\text { understood as the remaining level of PTI (and } \\
\text { weak ETI) in a susceptible (compatible) } \\
\text { interaction, where several immune responses of } \\
\text { PTI are suppressed by effectors. Basal resistance } \\
\text { cannot protect the plant against pathogens, but } \\
\text { restricts its level of virulence. Mutants lacking } \\
\text { components of basal defense show enhanced } \\
\text { susceptibility to already virulent pathogens. }\end{array}$ \\
\hline Preinvasive immunity & Postinvasive immunity \\
\hline $\begin{array}{l}\text { One of the first steps during an infection cycle is the } \\
\text { penetration of host tissues. Microbes grow epiphytically } \\
\text { on plant surfaces from where they enter into the plant } \\
\text { tissue. Preinvasive immunity consists of pre-existing } \\
\text { physical and chemical barriers such as the leaf cuticle } \\
\text { and tissue architecture, as well as inducible barriers } \\
\text { provided by PTI, e.g., stomatal closure and protects } \\
\text { plant tissues from microbial invasion. }\end{array}$ & $\begin{array}{l}\text { Inside plant tissues, the pathogen is exposed to } \\
\text { further layers of plant defense. These layers } \\
\text { consist of responses provided by PTI and ETI. } \\
\text { The pathogen needs to suppress postinvasive } \\
\text { immunity in order to access nutrients and } \\
\text { multiply. Completion of the pathogen's life } \\
\text { cycle is important for release out of the host and } \\
\text { further transmission of the pathogen to new } \\
\text { host plants. }\end{array}$ \\
\hline
\end{tabular}

\footnotetext{
${ }^{1}$ This table gives the current definitions of important terms used to describe several layers of plant immunity. Contrasting or parallel concepts opposed to each other are on the two sides of the table.
}

Nonhost resistance: resistance to pathogens that are virulent on other host plants, no macroscopic symptoms, PTI/weak ETI contribute to nonhost resistance

\section{ETI (effector-} triggered immunity): plant immune responses triggered by $\mathrm{R}$ proteins upon recognition of cognate effectors, reinforcement of PTI, classically known as gene-for-gene resistance

HR: hypersensitive response

PCD: programmed cell death [guard hypothesis (109)] of effector molecules and override suppression of PTI by reinforcement of immune responses, resulting in ETI (effector-triggered immunity, Table 1). Typically, ETI is associated with a hypersensitive response (HR)/PCD (programmed cell death) and systemic acquired resistance $(8,19,23) . R$ gene-mediated resistance is race specific and classically known as gene-for-gene resistance (33). Nonetheless, this level of resistance can be overcome by some pathogens, which have evolved effectors to inhibit ETI-mediated cell death. In return, these effectors can be recognized by cognate $\mathrm{R}$ proteins triggering resistance (54) leading to an evolutionary arms race between pathogen virulence and plant defense.

The impact of effectors in the context of ETI (gene-for-gene resistance) has long been studied, whereas suppression of PTI by effector molecules became a major research topic only relatively recently. Therefore, we focus on the latest findings and highlight mechanisms employed by pathogens to suppress PTI. First, we summarize methods that are used to identify such effectors and explain why different methods can lead to contradictory results. In the second part, we place effectors according to their mechanism of action into individual layers of defense ranging from overcoming preinvasive immunity (Table 1) to suppression of PTI and downstream signaling of postinvasive immunity (Table 1). Furthermore, to unify definitions, Table 1 gives an overview of the most important terms used to describe plant immunity.

\section{METHODS FOR IDENTIFYING EFFECTORS SUPPRESSING PLANT DEFENSE RESPONSES}

The identification of effectors that suppress PTI is challenging because individual layers of defense reactions cannot easily be uncoupled from each other, and often in plant-pathogen interactions PTI overlaps with ETI. Besides characterization of individual effector molecules and bioinformatic predictions, several reporter monitoring systems, growth assays, and staining of defense outputs are used to 
identify effectors interfering with PTI, which are summarized together with biochemical function and target proteins in Table 2.

Ongoing sequencing of genomes enables bioinformatic prediction of effectors in an increasing number of pathogens. Based on the features of known effectors, candidates should be small, secreted proteins, which are rich in cysteines and show no obvious homology to known proteins. Besides a signal peptide, the RxLR (Arginine, any amino acid, leucine, arginine) motif is involved in secretion of oomycete effectors. In Phytophthora sojae, Phytophthora ramorum, and Hyaloperonospora parasitica draft genomes allowed identification of effector inventories using this RxLR motif (114a). Predicted effectors have to be analyzed in functional assays to confirm their role in virulence and to elucidate their molecular mechanism.

NHO1, FRK1/SIRK, and RAP2.6 are wellcharacterized PAMP-induced genes and therefore frequently used as markers for defense responses in Arabidopsis thaliana. NHO1 is required for basal resistance (Table 1) against Pseudomonas (70). Its expression is induced upon stimulation with flagellin. Virulent pathogens alter this transcriptional induction of $\mathrm{NHO1}$ by delivery of effectors. This process was studied in a mesophyll protoplast system carrying an NHO1 promoter-luciferase fusion construct, in which individual effectors were transiently expressed. HopS1, HopAI1, HopAF1, HopT1-1, HopT1-2, HopAA1-1, HopC1, or AvrPto (AvrPto1) suppress flg22induced expression of $\mathrm{NHO1}$ (64), suggesting a role in suppression of PTI. Similarly, an FRK1 (FLG22-INDUCED RECEPTOR-LIKE KINASE 1) promoter-luciferase reporter construct was developed in mesophyll protoplasts to monitor flg22 signaling. FRK1 is rapidly induced upon flg22 perception (5). AvrPto and AvrPtoB (HopAB2) suppress flg22-mediated FRK1 induction, whereas other known suppressors of PTI such as HopAO1, HopE1, and HopK1 (45) have no effect.

Although providing a rapid assay, transient expression in protoplasts has some limitations: Effector proteins do not necessarily accumu- late to the same concentration reached in a real infection. Also, defense signaling might be changed in protoplasts compared to the in planta situation. To overcome the limitation of protoplasts, a promoter-luciferase fusion of the ethylene response factor (ERF) gene, RAP2.6, was developed in planta. In contrast to NHO1 and FRK1, RAP2.6, an ERF family transcription factor, is strongly up-regulated upon infection by virulent strains of Pseudomonas. In these RAP2.6 reporter lines, AvrB, AvrRpt2, HopAR1, HopPtoK, and HopX1 contribute to $R A P 2.6$ induction when delivered by virulent pathogens (44). Loss of virulence, e.g., in T3SS mutants $(b r c C)$, was also visualized as reduced luciferase activity. The drawback to this system is the use of a single reporter gene, which renders this assay highly specific to one particular signaling pathway. Nevertheless, this in planta assay mimics the situation of a natural infection much better than protoplast-based systems.

Instead of using reporter constructs, immune responses themselves can be monitored to identify effectors. ROS production is an early defense response triggered immediately upon PAMP perception, which can be followed by luminescence assays. Effectors such as AvrPto and AvrPtoB suppress PAMP-triggered accumulation of ROS, when they are transiently expressed in Nicotiana benthamiana (42). As mentioned above, transient expression bears limitations. Furthermore, heterologous systems may contain different signaling components leading to changes in output.

Individual defense responses can also be followed by simple staining procedures, which allow fast estimation of the action of a given pathogen or effector. Callose deposition, a typical output of most signaling pathways, can easily be assessed by Aniline blue staining. PAMP-triggered callose deposition is suppressed, for example, by pathogen-delivered HopM1 and AvrE (25) or by inducible in planta expression of AvrPto (43). In N. benthamiana, vascular flow in minor veins is reduced during PTI triggered by Pseudomonas syringae pv. fluorescens $(P f l)$. This was visualized using the dye neutral red. Some effectors such as AvrPto,
Preinvasive immunity: physical/ chemical barriers and inducible reactions (PTI) preventing pathogens from gaining access to host tissue

Postinvasive immunity: inducible cellular defense responses provided by PTI/ETI that restrict pathogen in completion of their life cycle

Basal resistance: immunity that still occurs in susceptible interactions, does not protect the plant, but restricts pathogen's virulence

flg22: 22-amino acid elicitor active epitope of bacterial flagellin 
Table 2 Effector molecules and their function in suppression of defense ${ }^{1}$

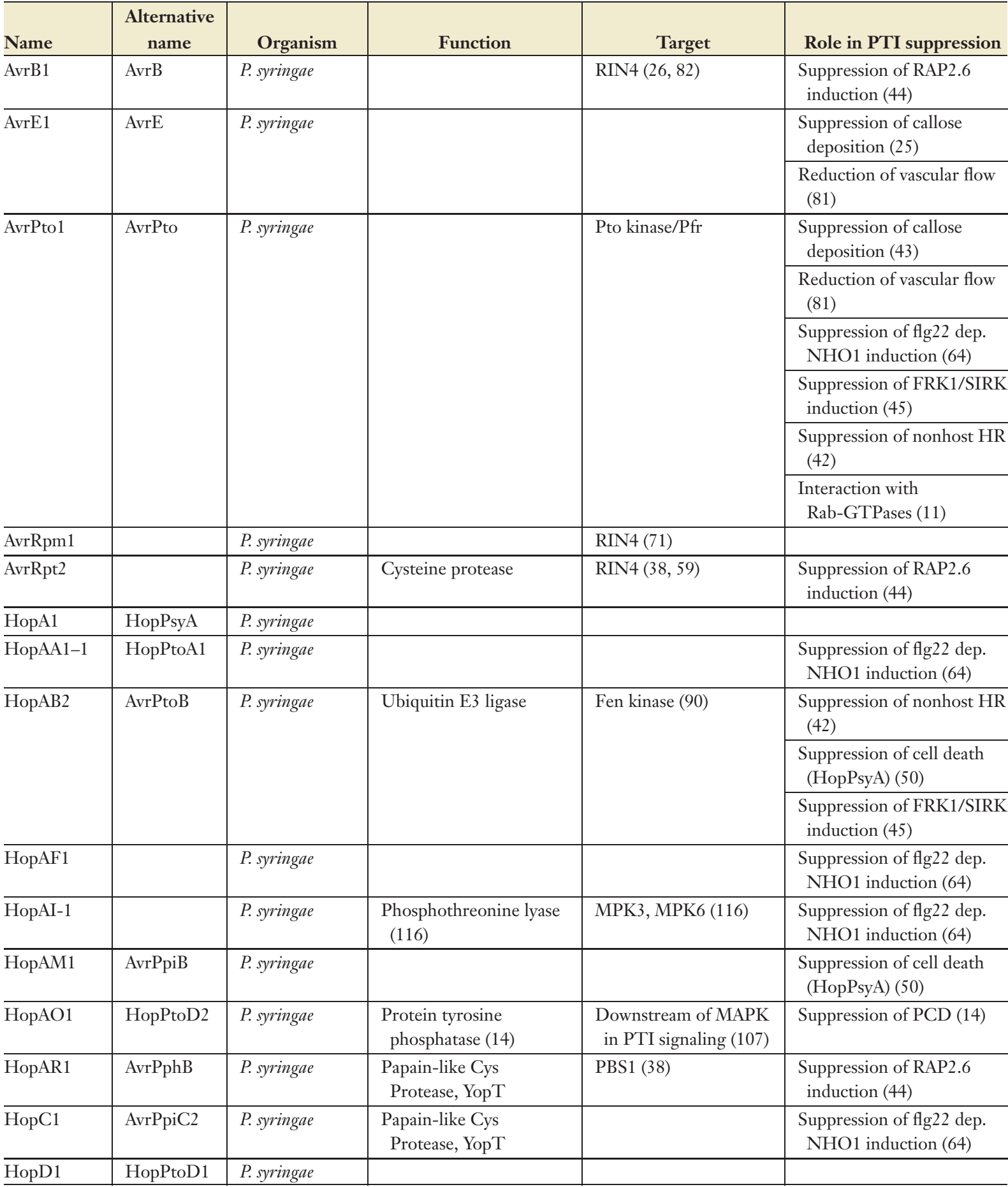


Table 2 (Continued)

\begin{tabular}{|c|c|c|c|c|c|}
\hline Name & $\begin{array}{c}\text { Alternative } \\
\text { name }\end{array}$ & Organism & Function & Target & Role in PTI suppression \\
\hline $\begin{array}{l}\text { HopE1 } \\
\text { HopPtoE }\end{array}$ & HopE & P. syringae & & & $\begin{array}{l}\text { Suppression of cell death } \\
\text { (HopPsyA) (50) }\end{array}$ \\
\hline HopF2 & AvrPphF & P. syringae & & & $\begin{array}{l}\text { Reduction of vascular flow } \\
(81) \\
\text { Suppression of cell death } \\
\text { (HopPsyA) (50) }\end{array}$ \\
\hline HopG1 & HopG & P. syringae & & & $\begin{array}{l}\text { Reduction of vascular flow } \\
\text { (81) }\end{array}$ \\
\hline HopK1 & HopPtoK & P. syringae & & & $\begin{array}{l}\text { Suppression of RAP2.6 } \\
\text { induction (44) }\end{array}$ \\
\hline \multirow[t]{2}{*}{ HopM1 } & \multirow[t]{2}{*}{ HopPtoM } & \multirow[t]{2}{*}{ P. syringae } & \multirow[t]{2}{*}{$\begin{array}{l}\text { Adaptor for } \\
\text { Ubiquitination } \\
\text { machinery }\end{array}$} & \multirow[t]{2}{*}{ MIN7 (78) } & $\begin{array}{l}\text { Suppression of callose } \\
\text { deposition (25) }\end{array}$ \\
\hline & & & & & $\begin{array}{l}\text { Reduction of vascular flow } \\
(81)\end{array}$ \\
\hline HopN1 & HopPtoN & P. syringae & $\begin{array}{l}\text { Papain-like Cys } \\
\text { Protease, YopT (69) }\end{array}$ & & \\
\hline HopO1-1 & HopPtoS1 & P. syringae & $\begin{array}{l}\text { mono-ADP- } \\
\text { ribosyltransferase } \\
(34)\end{array}$ & Chloroplast protein (34) & \\
\hline HopO1-2 & HopPtoS3 & P. syringae & $\begin{array}{l}\text { mono-ADP- } \\
\text { ribosyltransferase } \\
(34)\end{array}$ & Chloroplast protein (34) & \\
\hline HopS1 & HolPtoZ & P. syringae & & & $\begin{array}{l}\text { Suppression of flg22 dep. } \\
\text { NHO1 induction (64) }\end{array}$ \\
\hline Hop'T1-1 & HolPtoU1 & P. syringae & & & $\begin{array}{l}\text { Suppression of flg22 dep. } \\
\text { NHO1 induction (64) }\end{array}$ \\
\hline HopT1-2 & HolPtoU2 & P. syringae & & & $\begin{array}{l}\text { Suppression of flg22 dep. } \\
\text { NHO1 induction (64) }\end{array}$ \\
\hline HopU1 & HopPtoS2 & P. syringae & $\begin{array}{l}\text { mono-ADP- } \\
\text { ribosyltransferase } \\
(34)\end{array}$ & $\begin{array}{l}\text { RNA-binding proteins } \\
\text { (AtGrp7, AtGrp8) (34) }\end{array}$ & \\
\hline HopX1 & AvrPphE & P. syringae & Cysteine protease (77) & & $\begin{array}{l}\text { Suppression of cell death } \\
\text { (HopPsyA) (50) } \\
\text { Suppression of RAP2.6 } \\
\text { induction (44) }\end{array}$ \\
\hline Coronatine & & P. syringae & JA mimic (72) & & $\begin{array}{l}\text { Promotes reopening of } \\
\text { stomata }(72)\end{array}$ \\
\hline AvrBsT & & $\begin{array}{l}\text { X. campestris } \\
\text { pv. vesicatoria }\end{array}$ & $\begin{array}{l}\text { YopJ-like SUMO } \\
\text { protease }(22)\end{array}$ & & \\
\hline AvrRxv & & $\begin{array}{l}\text { X. campestris } \\
\text { pv. vesicatoria }\end{array}$ & $\begin{array}{l}\text { YopJ-like SUMO } \\
\text { protease }\end{array}$ & $\begin{array}{l}\text { Cytoplasmic target ? } \\
\text { (12) }\end{array}$ & \\
\hline AvrXv4 & & $\begin{array}{l}\text { X. campestris } \\
\text { pv. vesicatoria }\end{array}$ & $\begin{array}{l}\text { YopJ-like SUMO } \\
\text { protease }(86)\end{array}$ & Cytoplasmic target (86) & \\
\hline
\end{tabular}


Table 2 (Continued)

\begin{tabular}{|c|c|c|c|c|c|}
\hline Name & $\begin{array}{c}\text { Alternative } \\
\text { name }\end{array}$ & Organism & Function & Target & Role in PTI suppression \\
\hline XopD & & $\begin{array}{l}\text { X. campestris } \\
\text { pv. vesicatoria }\end{array}$ & SUMO protease & $\begin{array}{l}\text { Transcription factors? } \\
(48)\end{array}$ & $\begin{array}{l}\text { Structural determinants for } \\
\text { substrates (20) }\end{array}$ \\
\hline AvrBs3/PthA & & Xanthomonas & Transcription factor & Upa-box (58) & \\
\hline$\overline{\text { AvrBs2 }}$ & & Xathomonas & $\begin{array}{l}\text { Glycerophosphoryl } \\
\text { diester phosphor- } \\
\text { diesterase (100) }\end{array}$ & & \\
\hline$\overline{\mathrm{PopP} 1}$ & & R. solanacearum & $\begin{array}{l}\text { YopJ-like SUMO } \\
\text { protease (63) }\end{array}$ & & \\
\hline$\overline{\mathrm{PopP} 2}$ & & R. solanacearum & $\begin{array}{l}\text { YopJ-like SUMO } \\
\text { protease (63) }\end{array}$ & & \\
\hline$\overline{\text { GALA }}$ & & R. solanacearum & $\begin{array}{l}\text { F-box proteins, } \\
\text { ubiquitinaion (2) }\end{array}$ & & \\
\hline \multirow[t]{2}{*}{$\overline{\mathrm{DspA} / \mathrm{E}}$} & & E. amylovora & & & $\begin{array}{l}\text { Interaction with LRR-RLK } \\
\text { (73) }\end{array}$ \\
\hline & & & & & $\begin{array}{l}\text { Suppression of callose } \\
\text { deposition, delay of } \\
\text { defense gene expression } \\
\text { (13) }\end{array}$ \\
\hline$\overline{\text { AVRa10 }}$ & & B. graminis & Penetration (84) & & \\
\hline$\overline{\mathrm{AVRk} 1}$ & & B. graminis & Penetration (84) & & \\
\hline$\overline{\text { Avr2 }}$ & & C. fulvum & $\begin{array}{l}\text { Cysteine protease } \\
\text { inhibitor (88) }\end{array}$ & Rcr3 & \\
\hline$\overline{\text { Avr4 }}$ & & C. fulvum & $\begin{array}{l}\text { Chitin binding lectin } \\
(108)\end{array}$ & Chitinase & \\
\hline
\end{tabular}

\footnotetext{
${ }^{1}$ This table summarizes effectors as mentioned in the text providing alternative names and their organism of origin. When no specification is given (P. syringae, Xanthomonas), the effector is present in several pathovars of the pathogen. Biochemical function and the effector targets are known for a subset of the effectors, but various methods have been used to characterize the role in PTI suppression.
}

AvrE, HopM1, HopF2 and HopG1, delivered via the T3SS of $P f l$, re-establish vascular flow whereas HopC1 does not (81).

To avoid reliance on an individual immune response, bacterial growth rates can be used as a general output for virulence of a given pathogen. Enhanced or retarded multiplication of pathogens is used in a number of studies, where effectors are either expressed ectopically in planta, delivered by avirulent pathogens $(40,114)$, or deleted from virulent pathogens. Effectors such as AvrRpm1, HopM1, or effector cluster deletions have been characterized in such systems (6). Induced expression of effectors in transgenic plants might be misleading, since overexpression or wrong timing might result in unspecific activities. In addition, effec- tor activity might require modifications that are only obtained upon expression and delivery by the pathogen. Delivery of effectors via model pathogens overcomes several of these problems and are used to study effectors of pathogens, where molecular manipulation is limited. Secretion of the $H$. parasitica effectors ATR1 and ATR13 as fusion proteins with the endogenous T3SS signal sequence by $P$. syringae pv. tomato (Pst) into Arabidopsis leads to enhanced virulence in susceptible Arabidopsis accessions and triggers HR in resistance accessions (83a, 96a). Such an "effector-vector-detector" system allows not only further characterization of known effectors, but also identification of new ones.

PCD is triggered upon recognition of an effector during HR mediated in the frame of 
ETI and therefore can serve as readout to screen for effector molecules. PCD was used to analyze the effector repertoire of the bean pathogen P. syringae pv. syringae $\mathrm{B} 728 \mathrm{a}$ in a comparative study (111). To proliferate, biotrophic pathogens have to ensure host cell survival and hence suppress PCD. Screens for effectors that can suppress PCD have been carried out in tobacco and Arabidopsis: HopE1, HopX1, HopAM1, AvrPtoB, and HopPtoF interfered with HopPsyA-dependent HR (50). Even though HR is considered a hallmark of ETI, PTI always precedes ETI and thus PCDsuppressing effectors not only interfere with ETI, but might also target PTI. Interestingly, these effectors also interfere with Bax-induced PCD in yeast (50). The conservation of the antiPCD activity of these effectors opens up a wide range of easy-to-handle, heterologous systems for initial identification of effectors.

In general, effectors active in any of these systems are good candidates for PTI suppressors, and most known effectors have been characterized in one or several of the assays. However, limitations of the individual systems have to be considered and can provide explanations for contradictory results. Since most of the reporters are localized downstream in defense responses, little information is gained about the mechanism of action. In addition, effectors acting at redundant upstream steps might be missed in these assays. Therefore, the role of individual effectors during the infection process should be confirmed by pathogenicity tests of corresponding deletion mutants of the pathogen strain. However, since pathogens express a battery of effectors, single deletion mutants may not always cause obvious effects.

\section{EFFECTORS INTERFERE WITH PLANT IMMUNITY AT MULTIPLE LEVELS}

Improvements in bioassays have facilitated identification of whole effector repertoires of pathogens in ever-increasing numbers. However, identification of the targets and the mechanism by which these effectors interfere with immunity is lagging behind. Here we place effectors according to the level of defense they interfere with. We also show how the same defense response can be targeted by effectors with different mechanisms.

An overview of plant defense barriers and responses that are targets of microbial effectors is illustrated in Figure 1. These effectors can act at pre-existing barriers and any level of PTI. They may promote entry and persistence in the apoplast, prevent recognition of PAMPs, hinder activation of PRRs, interfere with downstream signaling, stop defense responses, or alter defense gene expression. Although fungi, oomycetes, and viruses cause major economic damage (4), bacteria are still the best characterized phytopathogens to date. Several genomes are available, e.g., P. syringae pvs. tomato, phaseolicola, and syringae, Ralstonia solanacearum, Xanthomonas campestris vesicatoria, X. oryzae oryzae, Xylella fastidiosa, or are being sequenced (http:// www.tigr.org/ vinita/Ppwebpage.html), and effector inventories are available for $P$. syringae $(67,92)$ and $X$. campestris vesicatoria $(38)$. Thus, most of our information on suppression of PTI results from bacterial effectors.

\section{Overcoming Physical Barriers of Preinvasive Immunity}

During epiphytic growth on the leaf surface, bacteria grow in biofilms, which involves quorum sensing. The effector AvrXa21, expressed by Xanthomonas oryzae oryzae, seems to play a role in quorum sensing, suggesting that control of proliferation during this growth phase is important for pathogenesis. In resistant rice cultivars, AvrXa21 is sensed by the RLK Xa21, which indicates that plants monitor surface colonization as a first step in defense (63a).

Following proliferation on the surface, pathogens have to overcome physical barriers or use natural openings to enter the plant tissue. However, the latter are well guarded in plants. During active photosynthesis stomata are open to allow efficient gas exchange. Bacteria are able to sense organic compounds 
relased during gas exchange and move toward stomata in order to penetrate the leaf tissue. The guard cells of stomata express PRRs. Upon contact with pathogens, PAMPs, such as bacterial flagellin or lipopolysaccharides (LPS), are perceived by PRRs and signaling cascades that lead to immediate stomatal closure are induced. As a result, entry of pathogens is pre- vented. Phytohormones such as jasmonic acid (JA) and abscisic acid (ABA) play a role in stomata opening/closure (68). To reopen stomata and gain access to the apoplast, bacteria secrete coronatine (COR), a polyketide phytotoxin that is structurally related to JA (72). COR might interfere with JA signaling, for example, by manipulating COI1, a plant F-box protein

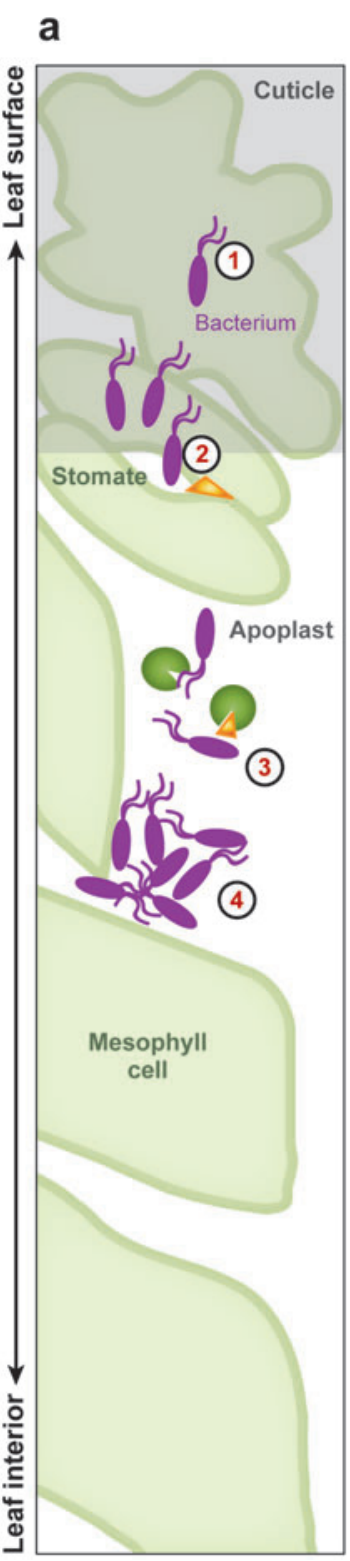

b

b Plasma

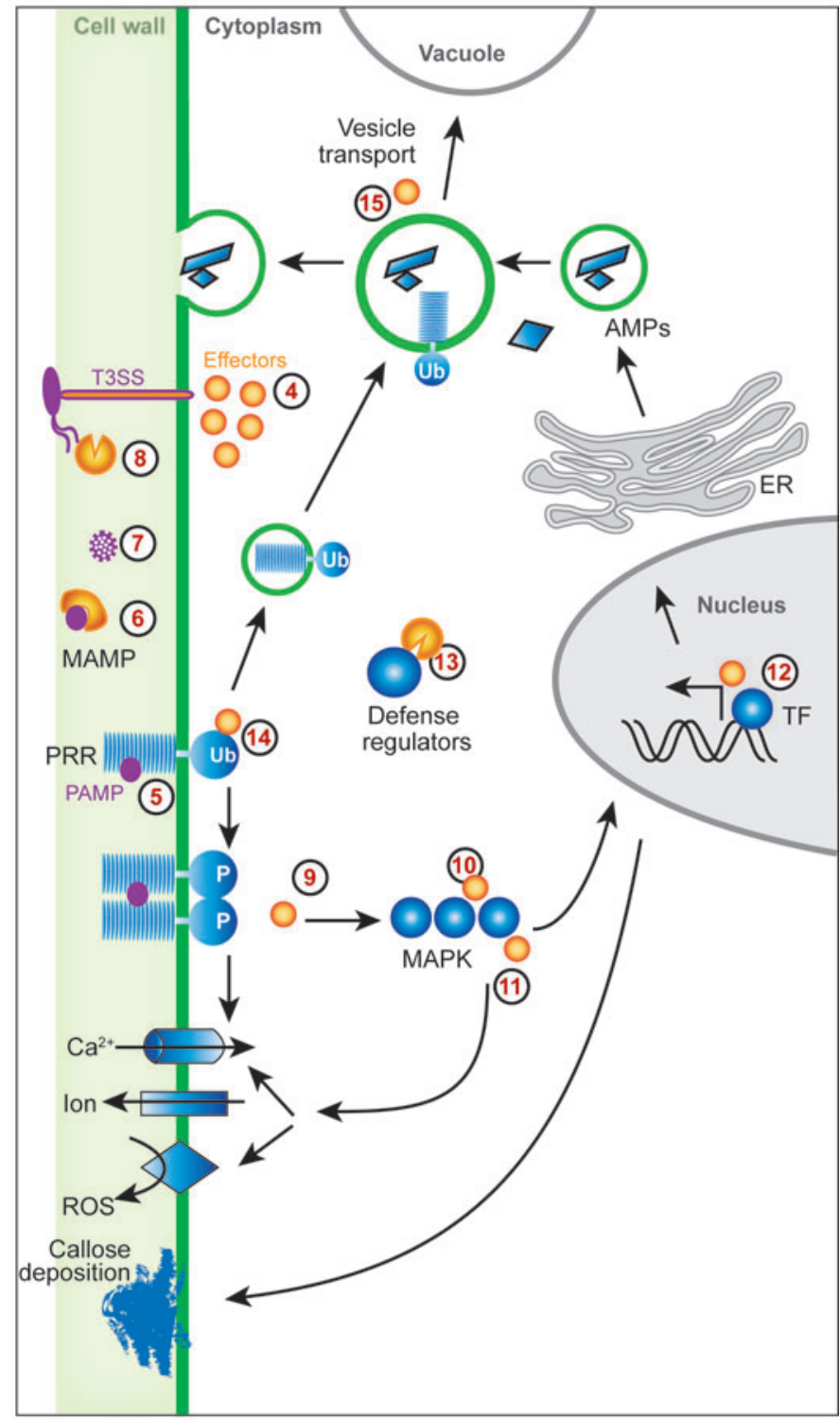


involved in the SCFCOI1 E3 ubiquitin ligase complex. This SCF complex targets jasmonateZIM-domain (JAZ) proteins for degradation, thereby releasing JA-responsive genes that are under negative control by JAZ repressors (103a). To close stomata during drought stress, the AtRac1 GTPase is inactivated, which maintains the actin cytoskeleton in guard cells. The resulting destabilization of the cytoskeleton leads to stomatal relaxation and thus closure (63b). A similar system might be involved in biotic stress. Interfering with destabilization of the actin cytoskeleton, e.g., degradation of negative regulators of Rho GTPases by the $\mathrm{SCF}^{\mathrm{COI}}$ complex, might ensure opening of stomata and allow entry of bacteria into the apoplast.

To multiply in the apoplast, pathogens can modify the conditions present in this environ- ment. For example, under drought stress of the plant, humidity in the apoplast is also limiting for bacterial growth. Therefore, HopAM1 is injected into the cells. It enhances ABA signaling and thereby not only downregulates a subset of defense responses, but also induces stomatal closure, thus protecting developing bacterial colonies against osmotic stress (35a). This prevents further entry of bacteria into the leaf and hence might protect the niche for the resident bacteria against entry of other competing pathogens.

In contact with plant cells, pathogens encounter the next physical barrier, the plant cell wall, that has to be penetrated to gain access to plant nutrients (112). Bacteria establish a T3SS, which spans cell wall and plasma membrane to get in contact with the cytoplasm. During formation of the T3SS, several

Figure 1

Bacterial effectors modify defense mechanisms and PTI signaling at any given level. (a) A plant leaf is schematically shown as top view $(t o p)$ from cuticle and epidermis to cross-section through the apoplast and mesophyll cells (bottom). (b) A cross-section through one enlarged cell.

1. Bacteria (purple) grow epiphytically on the surface of leaves and are prevented from entry by the cuticle ( gray) (49).

2. They swim toward openings such as stomata, where they enter the plant tissue (106). Stomata are closed upon PAMP recognition, but effectors (orange), e.g., coronatine, lead to reopening (72).

3. Bacteria enter the intercellular space and encounter enzymatic barriers such as proteases and cell wall-degrading enzymes. Secretion of inhibitors (orange triangle), e.g., Kazal and Cystain protease inhibitors, protect the pathogen $(104,105)$.

4. Bacteria adapt their lifestyle to the apoplastic space, settle in between cells, with the help of effectors gain access to water and nutrients, and multiply. PAMPs (purple circles) are released during pathogen growth as degradation or secretion products or result from dying bacteria.

5. Recognition of PAMPs leads to activation of defense responses (blue) such as ion fluxes, ROS production, callose deposition, and secretion of antimicrobial compounds (AMPs). Signaling requires $\mathrm{Ca}^{2+}$ fluxes and involves activation of MAPK cascades $(8,37)$.

6. PAMPs are masked or degraded to evade recognition (orange), e.g., bacterial peptidoglycans degraded by HopP1 (80). Lipopolysaccharides might form a protective layer to prevent diffusion of PAMPs to PRRs (103).

7. Some pathogens have adapted PAMPs (camouflage) that render them no longer recognizable by plant receptors $(31,83,98)$.

8. Bacteria form a T3SS through which they pass effectors (orange circles) into the plant cell (15). Penetration of the T3SS is promoted by the action of degrading enzymes, e.g., cellulases, cellobiosidases, and lipases (52).

9. Effectors like AvrPto and AvrPtoB interfere with receptor activation or early PAMP signaling $(42,45,102)$.

10. Signaling via MAPKs is suppressed by effectors like HopAI1 (116) and

11. HopAO1, which probably acts downstream of the MAPK cascade $(14,107)$.

12. Many defense reactions involve transcriptional changes, thus, effectors manipulate the defense transcriptome. HopU1 interferes with RNA binding proteins (34). Effectors such as XopD inactivate plant transcription factors $(47,75,86)$. Members of the AvrBs3 family are themselves transcriptional activators $(35,58)$.

13. To degrade host proteins, several cysteine and serine proteases are secreted by bacterial pathogens, e.g., HopAR1 and AvrRpt2 (38).

14. Effectors also modulate the plant ubiquitination/proteasomal degradation system as reported for AvrPtoB (90).

15. Vesicle trafficking plays an important role in PTI, e.g., secretion of AMPs and endocytosis of PRRs. AFR-GEFs are involved in vesicle trafficking and can be sent for proteasomal degradation by effectors such as HopM1 (78). 
lytic enzymes are produced that degrade the tight cell wall structure. Xanthomonas oryzae oryzae secrete cell wall-degrading enzymes via the type-two secretion system: ClsA, a cellulase; Cbs, a cellobiosidase; and LipA, a lipase. During local degradation of the cell wall by these enzymes, which loosen the tight structure of the cell wall and open the plasma membrane, the T3SS is formed in the resulting channel. However, these enzymes in turn can trigger defense responses either by production of DAMPs (damage-associated molecular pattern) from the cell wall or by action as PAMPs themselves (52). Therefore, effector molecules, as yet unknown, are secreted to suppress this defense pathway (52). The fact that effectors are required to overcome the physical barrier of the plant cell wall, but at the same time their action triggers inducible defense responses, which in turn have to be suppressed by a following set of effectors, nicely illustrates the importance of proper orchestration of effector secretion.

For some fungi (e.g., Blumeria graminis, Magnaporthe grisea, Erysiphaceae spp.) and oomycetes (e.g., Phytophthora spp.), spores germinate on the plant surface, build germination hyphae, and finally form appressoria to force their way through the cell wall by localized physical pressure. Penetration can be assisted by degrading enzymes, for example, pectolytic enzmyes or cutinases. The penetration hyphae continue to grow intercellularly and finally form haustoria inside plant cells (79). The barley powdery mildew fungus Blumeria graminis secretes at least two effectors, AVRa10 and AVRk1, that increase the penetration rate in susceptible hosts (84). They appear to be localized in the plant cytoplasm, but their mechanism of action is unclear.

\section{Inhibiting Enzymatic Degradation in the Apoplast}

In addition to organ and tissue integrity and to the protective layer of the cell wall, the plant apoplast contains destructive enzymes, which are inoffensive to the plant itself, but can attack structural components of pathogens. In this way, proteases, cell wall-degrading enzymes, and hydrolases attenuate pathogen persistence. Diverse plant cysteine and serine proteases are part of the apoplastic defense. As protection against such proteases, during infection the fungus Cladosporium fulvum releases the cysteine protease inhibitor Avr2 into the apoplast, which inhibits the tomato protease Rcr3 by directly binding to it (88). However, in resistant plants, this complex Avr2-Rcr3 is recognized by the $\mathrm{R}$ protein Cf-2, resulting in activation of $\mathrm{HR}$. Phytophthora infestans, an oomycete pathogen, secretes several inhibitors of the Cystain and Kazal family of protease inhibitors: EPIC2B inhibits the cysteine protease PIP1, and its homolog EPIC1 is predicted to act in a similar manner. EPI1 and EPI10 inhibit the serine protease P69B $(104,105)$. By protecting themselves against degradation, pathogens not only promote their persistance in the apoplast, but also prevent the display of PAMPs, e.g., cell wall fragments that would trigger PTI. Further characterization of secreted plant proteases and potential cognate pathogen inhibitors will enhance our understanding of defense and counterdefense in the apoplast.

Although degrading activities can be harmful to the pathogens, bacteria also secrete such enzymes, which act on the pathogen itself, in a controlled way. For example, to accommodate the T3SS, specialized lytic transglycosylases (LT) are required that degrade the bacterial peptidoglycan layer locally. However, during this process peptidoglycan fragments are produced that may act as elicitors of defense responses (39). Three LTs from P. syringae, $\mathrm{HrpH}$, HopAJ1, and HopP1, were recently characterized. $\mathrm{HrpH}$ is directly involved in accommodation of the T3SS, while HopP1 contributes to PTI suppression in the apoplast of $N$. benthamiana (80). HopP1 might sequester or process peptidoglycan fragments generated by the action of $\mathrm{HrpH}$ and thereby remove the elicitors preventing immune responses.

Degradation of the chitin cell wall by plant chitinases occurs in fungi and leads to the production of breakdown products that serve as PAMPs to alert the plant defense system. 
In C. fulvum a chitin-binding lectin, Avr4, specifically binds to the fungal cell wall and protects chitin against degradation (108). As a result, the fungus is protected against damage, and chitin fragments are kept from triggering PTI (65). Similarly, glucanases are secreted by plants to attack pathogens. The oomycetes Phytophthora sojae secretes glucanase inhibitor proteins that bind to plant glucanases during infection and thereby prevent release of oligoglucoside defense elicitors (89). These protease inhibitors of diverse pathogen origin exemplify how enzymatic defense in the apoplast is overcome and at the same time induction of PTI is prevented.

\section{Masking Elicitors}

As described above, PTI is mediated during early steps of pathogen attack by perception of highly conserved microbial patterns. PAMP elicitor active epitopes are recognized by cognate receptors. Alterations within the sequence of the elicitor active structures would allow loss of receptor activation or receptor recognition and thus would be an efficient masking of the PAMP. In most cases, however, mutating the pattern is difficult owing to its essential function for the pathogen. Nevertheless, Agrobacterium tumefaciens and $R$. solanacearum, for example, have modified their flagellins so that the elicitor epitope no longer stimulates PTI (31, 83). Similarly, X. campestris pv. campestris displays extremely high sequence variability in the flagellin, allowing it to avoid recognition (98).

Mechanisms of camouflage from rhizobia and arbuscular mycorrhiza are probably similar to those found in pathogens in that they have to overcome the same layers of preinvasive defense. The role of LPS as PAMPs in induction of defense responses (28) is inverted in the symbiosis between Sinorbizobium meliloti and Medicago truncatula: Instead of eliciting immune responses, LPS suppresses the production of ROS and transcriptional changes triggered by invertase, thereby promoting establishment of the symbiosis (103).
Structural variations in the LPS might make the difference between suppression and elicitation of PTI by symbionts, and pathogens respectively. Although alteration of PAMP sequences/structures is a highly efficient means to avoid immune responses, it is limited to a number of highly adapted pathogens. Resulting disadvantages in fitness, e.g., reduced movement if flagellar are mutated, might select against such alterations. It is important to note that in most cases the epitope recognized by PRRs corresponds to the most conserved region of the pathogen molecule, which hints at its essential function.

\section{Inhibition of Receptor Activation}

Once PAMPs are recognized by PRRs, the receptors are activated and immediately start defense signaling. Inactivation of the receptor by effectors efficiently blocks all downstream defense responses. AvrPto and AvrPtoB from $P$. syringae suppress flg22 signaling at an upstream step. When expressed ectopically in A. thaliana, AvrPto changes expression of $\sim 80 \%$ of all T3SS-regulated genes (43). Thus, it seems to be a major regulator of defense gene expression. AvrPto action leads to suppression of PAMP-mediated defense responses such as ROS production, MAPK activation, induction of defense genes, and callose deposition. Membrane localization of AvrPto is required for these effects (45). Suppression of MAPK activation can be overcome by ectopic expression of constitutively active MEKK1, one of the early downstream components in FLS2 signaling (45). Similarly, constitutively active MEKK1 also overcomes defense suppression caused by AvrPtoB, suggesting that AvrPtoB might also target upstream steps of PAMP signaling (45).

In tomato, AvrPto and AvrPtoB are recognized by the Pto kinase, which is guarded by the R protein Prf that elicits PCD (61). There are no homologues of Pto found in Arabidopsis. Instead, the kinase domains of FLS2, its co-receptor BAK1 (18), and EFR show significant sequence homology to Pto (Figure 2).
MAPK: mitogen activated protein kinase 


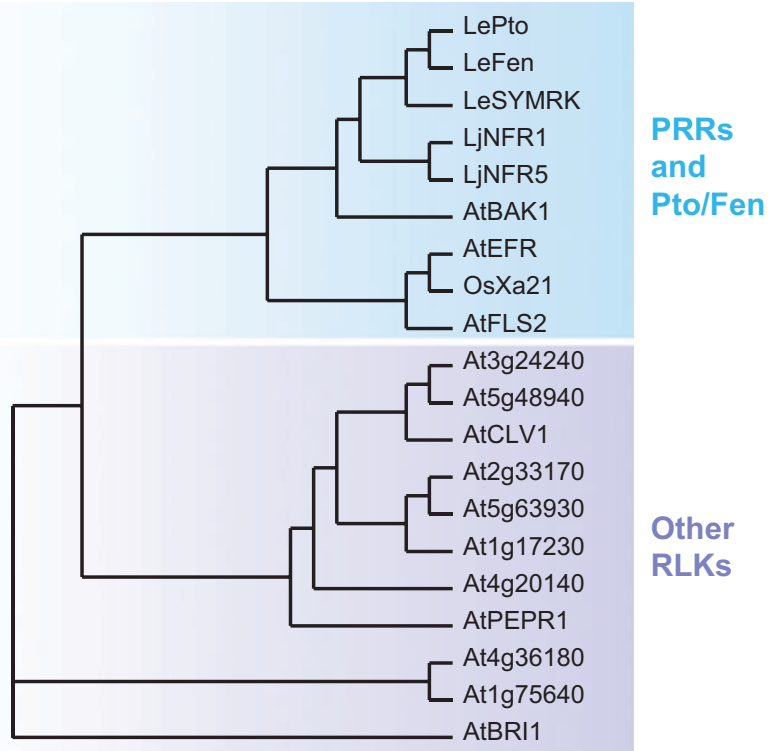

Figure 2

The closest homologs of Pto and Fen in Arabidopsis are kinase domains of PRRs. The unrooted phylogenetic tree was established based on a multiple sequence alignment of the protein kinase domains of Pto, Fen, several PRRs, and other RLKs using ClustalW (http://www.ebi.ac.uk/Tools/clustalw/index.html) and visualized using Treeview (http://taxonomy.zoology.gla.ac.uk/rod/ treeview.html). PRRs are in the same group as Pto and Fen, whereas other RLKs with possible functions in development are more distantly related. In Arabidopsis, BAK1 appears as the closest homolog of Pto and Fen. Hence, PRRs could be putative targets for effectors.

The crystal structure of the AvrPto-Pto complex was recently solved, and structural modeling supports the relevance of the similarity between Pto kinase and the FLS2 and EFR kinase domains (114b). This provides strong evidence that AvrPto targets PRRs. Indeed, AvrPto was found to physically interact with FLS2, EFR, and a so-far uncharacterized RLK (At2g23200) in vitro and in protoplasts. Interaction with AvrPto inhibited FLS2 and EFR in vitro autophosphorylation activity. As for the AvrPto-Pto complex, interaction of AvrPto with FLS2 and EFR also requires the conserved GINP motif (114b). It appears that multiple PRRs including co-receptors could be targets of AvrPto and most likely AvrPtoB as well.

Outside the Pto interacting domains, AvrPto and AvrPtoB show little sequence homology.
AvrPtoB carries an E3 ligase activity in its $\mathrm{C}$ terminus, which is absent in AvrPto. Ubiquitination of the Fen kinase, a member of the Pto family, by AvrPtoB targets it for degradation and thereby prevents ETI in the form of PCD in tomato plants lacking Pto (90). Interestingly, the Pto kinase is not a substrate of AvrPtoB, suggesting molecular differences in between these highly related kinases. Although molecularly different, according to functional similarities, AvrPtoB might target PRRs as does AvrPto.

Defense suppression of AvrPto and AvrPtoB is not limited to the flg22 pathway in $\mathrm{Ara}$ bidopsis. In N. benthamiana, flagellin perception leads to nonhost HR (102), which also can be suppressed by AvrPto and AvrPtoB (42). Similarly, nonhost HR elicited by INF1, the major secreted protein of the oomycete pathogen P. infestans, is suppressed by AvrPto and AvrPtoB (42). Thus, these effectors might block PTI signaling at the receptor level in other systems as well. Possible mechanisms include preventing activation via phosphorylation, receptor dimerization, complex formation with a co-receptor, or degradation.

A direct interaction between effector and PRR was also discovered in the Erwinia amylovora-apple interaction. DspA/E, a member of the AvrE family, interacts specifically and directly with four putative LRR-RLKs (73). Suppression of callose deposition and delay of defense gene expression by DspA/E (13) suggest that they might act in PTI suppression mediated by the interacting LRR-RLKs. Sequence prediction of $\mathrm{WtsE}$ from Pantoea stewartii and several homologs of the AvrE family identified a putative endoplasmic reticulum membrane retention signal (ERMRS), which is essential for viability (41). Presence of such a motif suggests localization of $\mathrm{WtsE}$ in the host endomembrane system, although this localization has not yet been confirmed. Since receptors are taken up by endocytosis as demonstrated for FLS2 (85) and exocytosis of AMPs is important for defense, AvrE might exert its function in subcellular vesicle trafficking (see below). 


\section{Downregulation of MAPK-Signaling}

Following PAMP perception, one major defense signaling pathway employs MAPK cascades, which have been especially well characterized for flg22 signaling. Asai et al. (5) proposed a model in which MEKK1 is stimulated by FLS2 and the signal is subsequently transferred via MKK4/5 to MPK3 and MPK6, which in turn activate WRKY22/29 transcription factors. However, the exact nature of the MAPK cascade is still under debate and alternative cascades may well be active in parallel $(74,97)$. Several effectors act at different steps of this signaling cascade in plant as well as animal pathogens (93). Dephosphorylation of any of the MAP kinases efficiently suppresses defense signaling. Two different mechanisms are known by which effectors dephosphorylate defense signaling components. HopAI1, a potent suppressor of $\mathrm{NHO1}$ upregulation (64), encodes a phosphothreonine lyase. HopAI1 alters threonine residues of MAPKs and thereby irreversibly blocks phosphorylation (116). MPK3 and MPK6, key MAPKs in the FLS2 pathway, are targets of HopAI1 and thus flg22 signaling is inhibited at an early step. Accordingly, downstream responses such as ROS production, callose deposition, and $P R$ gene expression are suppressed (116). HopAO1 (HopPtoD2) is a T3SS-dependent effector with protein tyrosine phosphatase activity that contributes to the virulence of bacteria by suppression of PCD (14). Its target is not known to date, but it is most likely activated by tyrosine phosphorylation. HopAO1 suppresses $P R$ gene expression and PCD when it is triggered by a constitutively active MKK in N. benthamiana (30). In contrast, HopPsyA or AvrRpt2-triggered PCD is not suppressed (107). HopAO1 was also reported to suppress PAMP-triggered ROS-production (14), callose deposition induced by a Pst hrpA mutant, and flg22-triggered resistance to Pst DC3000, but not to change activation of MPK3 and MPK6 (107). Therefore, HopAO1 most likely targets signaling components independent or downstream of the MAPK cascade, e.g., transcription factors. Thus, expression of only a subset of defense-related genes, many of which are also induced by JA, is inhibited by HopAO1.

\section{Modification of the Defense Transcriptome}

PTI includes massive changes in gene expression. For example, expression of about 1000 genes is changed after flg22 perception (118). Bacterial effectors not only interfere with PTI signaling but can also modify the plant defense transcriptome more directly. Various mechanisms are employed to alter RNA stability. For example, RNA-binding proteins are targeted to alter RNA turnover: HopU1 (HopPtoS2) is a mono-ADP-ribosyltransferase (ADP-RT) that acts on glycine-rich RNA-binding proteins such as AtGrp7 and AtGrp8 (34). AtGrp7, an RNA chaperone, is involved in several stress responses (cold, drought, salt, $\mathrm{ABA}$ ) regulating RNA turnover (17) and plays an important role in circadian rhythm (46). In addition, it functions in PTI, since grp 7 mutants in Arabidopsis are more susceptible to Pst DC3000 (34). By modification of the RNA chaperones AtGrp7 and AtGrp8, HopU1 can change the plant transcriptome and thus downregulate defense responses. Three other RNA-binding proteins have been identified as in vitro targets of HopU1 (34). Because of their localization in the chloroplast, they were not considered in planta targets at first. However, interfering with chloroplast gene expression might allow bacteria to optimize energy production for their own needs and limit it for plant defense purposes. In addition to HopU1, HopO1-1 (HopPtoS1) and HopO1-2 (HopPtoS3) encode ADPRTs, but they have not yet been functionally characterized.

Besides regulation of RNA levels via stabilization or destabilization of RNA binding proteins, RNA accumulation is also regulated by micro- and small interfering ( $\mathrm{mi}$ and si)RNAs. This process requires the action of ARGONAUTE (AGO) proteins, for example, AGO4-directed DNA methylation. Mutants in AGO4 are reduced in overall DNA 
methylation and are less resistant to the virulent pathogen Pst DC3000, the avirulent pathogen Pst DC3000 avrRpm1, and the nonhost pathogen P. syringae pv. tabaci (1). This implies that mi/siRNAs are involved in PTI and ETI. Furthermore, the plant miR393 is induced upon flg22 perception. It decreases transcript levels of the auxin receptor TIR1, thereby preventing degradation of Aux/IAA repressors, and is part of PTI by downregulation of auxin signaling (76). Another siRNA, Nat-siRNAATGB2, is induced by Pst DC3000 carrying avrRpt2 and contributes to ETI by removal of PPRL, a negative regulator of RPS2mediated resistance (57). Viral pathogens rely on the host machinery so that viral RNAs can accumulate. These are targeted for degradation by host siRNAs (66). Pathogens interfere therefore with $\mathrm{mi} / \mathrm{siRNA}$-regulated processes. Of the several known viral suppressors of RNA silencing, most bind to double-stranded RNA, the precursors of siRNAs (62). This prevents production of siRNAs and subsequent degradation of viral RNAs. Moreover, Polerovirus encodes the F-box protein P0 that mediates ubiquitination and degradation of AGO1, and thereby protects viral RNAs (7). Bacteria, fungi, and oomycetes might interfere with regulation of defense reactions by plant miRNAs in a similar way, e.g., by preventing generation of miR393 or Nat-siRNAATGB2, or by inhibiting AGO4.

Effectors of the AvrBs3 family seem to act more directly as transcriptional activators themselves. These effectors contain a plant nuclear localization signal, and targeting to the nucleus has been shown for some members of this family (101). A leucine zipper in these effectors may allow binding to DNA, and an acidic activation domain, which is required for virulence, induces host gene expression (38). The $X$. campestris pv. vesicatoria AvrBs3 effector protein binds to the upa-box (Upregulated by AvrBs3: upa) in various promoters and thereby activates transcription of Upa20, a master regulator of cell size, as well as other host genes. Pathogen transcription factors acting on the plant transcriptome could trigger expression of host pro- teins that ensure nutrient supply and thereby promote pathogen proliferation. In resistant pepper cultivars, however, the promoter of the cognate $R$ gene, $B s 3$, also carries the upa-box, leading to its transcription and subsequent induction of cell death (58). Thus, during evolution, plants appropriated the AvrBs3 cognate cis-element to counter defend themselves and induce resistance.

Pathogens also use the host's transcription and translation machinery to produce their own proteins directly in planta. This is well-known for viruses that express, e.g., RNA-polymerases or coat proteins with the help of the plant. Another example is Agrobacteria. They insert part of their DNA ( $\mathrm{tDNA}$ ) into the plant nucleus. This transfer process requires not only bacterial virulence factors such as VirE2, but also plant factors, e.g., karyopherin $\alpha$ or VIP1. VIP1 is a transcription factor that is phosphorylated by MAPKs upon PAMP perception and subsequently relocalizes to the nucleus to activate $P R$ gene expression. Agrobacteria-delivered tDNA is attached to VIP1 and via backpacking enters the plant nucleus. Thus, pathogens can utilize host signaling components to modify the host transcriptome and express their own proteins (27).

These examples illustrate some mechanisms by which pathogens influence RNA metabolism in the host cell. Such topics have only recently emerged, and further studies will enlarge our knowledge. In addition to interference with RNA binding proteins, siRNAs, transcription factor mimicry, degradation or inactivation of transcription factors (see below), or insertion of DNA, other steps of the transcriptome might be targeted. For example, splicing steps, RNA transport, or initiation of translation are further steps to manipulate the host's life.

\section{Degradation of Host Defense Components}

Microbial effectors can degrade antimicrobial compounds and various proteins that play a role in PAMP perception, PTI signaling, or 
defense reactions. Degradation can be achieved either via protease activity or by exploiting the plant proteasome degradation pathway (115). Effectors exhibiting protease activity directly target one or a group of host proteins. This offers the advantage that degradation can be carried out independently of host factors. Several effectors carry cysteine protease activity of various classes (YopJ/HopZ, XopD, YopT, AvrRpt2) (48). Some of the cysteine proteases such as XopD or members of the YopJ/HopZ family, e.g., AvrXv4 and AvrRxv show deSUMOylating activity. XopD accumulates in subnuclear foci (47) and therefore might be involved in transcriptional regulation by deSUMOylation of transcription factors. In contrast, AvrXv4 and AvrRxv localize in the cytoplasm $(12,86)$, but the targets of these effectors are unknown. HopZ family effectors require myristoylation for their virulence or avirulence activity (63b, 63c), suggesting membrane-localized targets. The mammalian pathogen homolog, YopJ, founding member of this family, interacts with MAPKs and plays a role in suppression of innate immunity (29), suggesting that this family might be involved in down-regulation of PTI signaling. However, recent findings question the role of YopJ as a cysteine protease, since acetylation of a MAPK by YopJ was observed (9).

Both HopAR1 (AvrPphB), a member of the YopT family, and AvrRpt2 function as cysteine proteases and cleave PBS1 and RIN4, respectively (38). Unfortunately, the role of these plant proteins in PTI is unclear even though they appear to act as general regulators that are well-guarded by several $\mathrm{R}$ proteins. RIN4 might act as an adaptor protein that holds multiple PRR signaling pathways under negative regulation (60). Its importance in defense is underlined by the number of effectors targeting RIN4: In addition to the protease AvrRpt2, AvrRpm1 (71) and AvrB (26, 82) bind RIN4. Furthermore, HopX (AvrPphE) (77) and HopPtoN (69), which suppresses nonhost HR when delivered by $P s t$ DC3000, are cysteine proteases with unknown targets.

\section{Exploiting the Host Proteasomal Degradation Machinery}

Protein degradation is also carried out by the proteasomal machinery. Exploitation of host proteasomal degradation has been extensively described for mammalian pathogens (3) and is also known for some plant pathogens. AvrPtoB is a modular protein consisting of an N-terminal domain (1-307) that interacts with Pto/Prf and triggers ETI. Its C terminus (387553) carries an E3 ligase activity. Homology between the $\mathrm{C}$ terminus of AvrPtoB and plant E3 ligases is low; only the crystal structure of AvrPtoB revealed striking similarities to plant U-box- and RING-finger-type E3 ligases (51). In addition, the middle domain (307-387) confers resistance mediated by Fen/Prf, which, however, is suppressed by the C-terminal E3 ligase activity (Resistance Suppressed by the C terminus of AvrPtoB: Rsb) due to ubiquitination and proteasomal degradation of the Fen kinase (90). Fen-triggered PCD involves the R-protein Prf and is therefore a component of ETI. Since AvrPtoB targets Fen for degradation leading to susceptibility of tomato plants, it is a good example of an effector interfering at the step of ETI in plant defense. Most likely, Fen is not the only target of AvrPtoBmediated ubiquitination. Virulence conferred by AvrPtoB depends on the presence of FLS2 (24), suggesting that this receptor and possibly other PRRs or their co-receptors might be targeted by AvrPtoB, as mentioned above. If this holds true, AvrPtoB interferes with two different immune responses, PTI and ETI. The modular constitution of AvrPtoB might reflect this dual function: The $\mathrm{N}$-terminal part (1-387) is sufficient to confer suppression of PTI and likely targets PRRs such as FLS2. This domain is homologous to HopPmaL from P. syringae pv. maculicola, which also downregulates defense (65a). In AvrPtoB the C-terminal E3 ligase activity suppresses PCD, a component of ETI (65a). Taken together, AvrPtoB might have evolved in several steps: Originally, the $\mathrm{N}$-terminal part of AvrPtoB carrying only PTI suppressing activity was sufficient to ensure 
virulence. In some tomato cultivars the Fen kinase might have evolved as a decoy to protect targets of AvrPtoB. In turn, AvrPtoB acquired a C-terminal addition to target Fen for degradation and to overcome ETI. In return, some tomato cultivars evolved another decoy, Pto, which functions similarly to Fen in mediating ETI via Prf, but resists AvrPtoB activity.

GALA effectors from $R$. solanacearum are modular proteins as well. They contain an Fbox domain and several LRRs. Because of their F-box, GALAs are able to interact with plant proteins to form an active SCF E3 ubiquitin ligase, which is required for virulence (2). The LRR domain carries the conserved GAxALA motif and seems to confer specificity as to which proteins are ubiquitinated. However, the targets of these effectors are not known. In silico analysis has already identified numerous additional effectors that carry F-box domains (3), implying a broader cooption of the plant's ubiquitination machinery for the purpose of degradation of host defense components.

\section{Interfering with Vesicle Trafficking}

Antimicrobial compounds are thought to be secreted by exocytosis (56). To prevent this secretion, effectors can act on proteins involved in vesicle trafficking and reroute their cargoes. HopM1 exploits the plant ubiquitination system to modify vesicle trafficking. It interacts specifically with MIN7, one of eight Arabidopsis ARF-GEFs (adenosine diphosphate ribosylation factor guanine nucleotide exchange factor) that play an important role in vesicle trafficking. This interaction leads to ubiquitination and degradation of MIN7 via the proteasome (78). Thus, transport of material required for callose deposition is prevented. A similar fungal effector might interfere with callose transport, which is required for papillae formation at fungal penetration sites (94) and thereby enhances penetration rates. In contrast to AvrPtoB and GALA7, HopM1 does not carry an enzymatic activity, but seems to act as an adaptor recruiting the plant ubiquitination machinery to MIN7 (78). Just like HopM1, AvrPto is also able to suppress callose deposition in an SAindependent manner (43). AvrPto might disturb vesicle trafficking in a manner similar to HopM1, since in yeast two-hybrid assays two Rab-GTPases were identified as interactors of AvrPto (11). An alternative target of AvrPto could be PRR-containing vesicles. Since AvrPto interacts with PRRs (114b), it might subsequently support or interfere with recruitment of components required for endocytosis. Increased endocytosis of PRRs could downregulate signaling and thereby suppress callose deposition and other defense responses indirectly.

\section{CONCLUSIONS}

Phytopathogens are highly adapted to the special conditions for in planta growth. This adaptation is also apparent from their large effector inventories: $P$. syringae pv. tomato DC3000 contains more than 30 T3SS effectors. Pseudomonas aeroginosa carries an effector repertoire that enables this pathogen to multiply in diverse hosts ranging from humans, mice, or C. elegans to Arabidopsis. Effectors have been found to interfere with each step of plant defense including pre-existing physical and chemical barriers as well as inducible PTI responses ranging from PAMP recognition, via defense signaling, to transcriptional changes, and even signaling via hormones. Defense responses are not the only targets of effectors. Cytoskeleton remodeling or changes in photosynthetic activity that limit pathogen proliferation are also likely to be modulated by effectors.

The defense reactions triggered by PRRs are not unique to PTI, but overlap with those involved in ETI. Therefore, allocation of effectors to one or the other pathway is difficult, if not impossible. General plant regulators of PTI such as RIN4 and PBS1 that are guarded by $\mathrm{R}$ proteins are at the connection point between both signaling pathways. If, as suggested, defense responses are triggered sequentially (54), effectors would have to overcome specific responses at specific times (16). Thus, bacteria might secrete effectors in a certain order, always modifying the next step in defense. 
Despite the diverse nature of pathogens, all of them have to manipulate processes of eukaryotic life. This becomes apparent from effectors of different pathogen origin exerting similar functions, e.g., proteasomal degradation, or that $H$. parasitica-derived effectors enhance bacterial virulence. Therefore, it seems that effectors are perfectly adapted to target nodes of eukaryotic processes, and further studies addressing effector targets and functions will enable us to better understand the innate immune system of higher plants.

\section{SUMMARY POINTS}

1. Plants defend themselves against pathogens through an extremely well-regulated, layered defense system. This is composed of preformed physical and chemical barriers, immediate responses upon pathogen contact, and temporally dispersed cellular and systemic reactions leading to increased resistance.

2. Successful pathogens can overcome this defense system by modifying components at any given step. For this purpose, effector molecules are secreted into plant tissue and cells. This secretion most likely follows a sequential order that is adapted to overcome the layered defense of plants.

3. Effectors can be identified by several reporter assays, effector inventories, and bioinformatic predictions. Frequently, effectors are modular proteins with several activities leading to overlapping or even contradictory results in predictions and reporter assays.

4. For a limited number of effectors the mechanisms of action and targets have been identified. A wide variety of enzymatic functions and host targets could be detected. Effectors appear highly adapted to eukaryotic processes. Therefore, effectors can promote pathogen virulence across microbial kingdoms.

5. Effectors themselves or effector actions can be recognized by plant $\mathrm{R}$ proteins that trigger ETI. However, successful pathogens modify their effectors or acquire novel ones to circumvent $\mathrm{R}$ protein monitoring. This leads to an evolutionary arms race in plantpathogen interactions.

\section{FUTURE ISSUES}

1. What is the effector inventory of any given pathogen? The effector inventories of fungi and oomycetes, in particular, are currently under investigation.

2. What is the minimal set to make a pathogen virulent? What is the set to reach maximal virulence? Has nature evolved both borders to its best or are the extremes disadvantageous in other regards?

3. What is the function and enzymatic mechanism of effectors in the plant cell? Only a subset of effectors modifies PTI. Others are involved in overcoming ETI or reprogramming the plant cell to optimize growth conditions for the pathogen, which is especially important for biotrophic pathogens.

4. Where are the effectors localized inside the plant cell? Localization could provide information about the role in adapting the plant to pathogen growth. 
5. Is there a hierarchy of secretion? Adaptation to timing of plant defense responses allows economy in synthesis of effectors.

6. What is the turnover of effectors in plant cells? High stability of effectors allows longlasting modification of the plant, whereas rapid degradation confers increased flexibility.

7. How do effectors evolve? Coevolution with plants adapts pathogens to their host but also limits the host range. Horizontal transfer of virulence factors between pathogens, even between different kingdoms, increases the repertoire and enables acquisition of new factors (99).

8. What determines host specificity in regard to effector inventories?

\section{DISCLOSURE STATEMENT}

The authors are not aware of any biases that might be perceived as affecting the objectivity of this review.

\section{ACKNOWLEDGMENTS}

We apologize to all investigators whose research could not be appropriately cited due to space limitations. We thank Thomas Colby for critically reading the manuscript and many colleagues for thoughtful discussions. The authors are supported by a grant of the Deutsche Forschungsgemeinschaft DFG (SFB 670).

\section{LITERATURE CITED}

1. Agorio A, Vera P. 2007. ARGONAUTE4 is required for resistance to Pseudomonas syringae in Arabidopsis. Plant Cell:10.1105\tpc.107.054494

2. Angot A, Peeters N, Lechner E, Vailleau F, Baud C, et al. 2006. Ralstonia solanacearum requires F-box-like domain-containing type III effectors to promote disease on several host plants. Proc. Natl. Acad. Sci. USA 103:14620-25

3. Angot A, Vergunst A, Genin S, Peeters N. 2007. Exploitation of eukaryotic ubiquitin signaling pathways by effectors translocated by bacterial type III and type IV secretion systems. PLoS Pathog. 3

4. APS. 2006. Microbial Genomic Sequencing Perspect. Am. Phytopathol. Soc. (Revised 2006). http://www.apsnet.org/members/ppb/PDFs/MicrobialGenomicsSeq06.pdf

5. Asai T, Tena G, Plotnikova J, Willmann MR, Chiu W-L, et al. 2002. MAP kinase signalling cascade in Arabidopsis innate immunity. Nature 415:977-83

6. Badel JL, Shimizu R, Oh H-S, Collmer A. 2006. A Pseudomonas syringae pv. tomato avrE1/hopM1 mutant is severely reduced in growth and lesion formation in tomato. Mol. Plant Microbe Interact. 19:99-111

7. Baumberger N, Tsai C-H, Lie M, Havecker E, Baulcombe DC. 2007. The polerovirus silencing suppressor P0 targets ARGONAUTE proteins for degradation. Curr. Biol. 17:160914

8. Bent AF, Mackey D. 2007. Elicitors, effectors, and $R$ genes: the new paradigm and a lifetime supply of questions. Annu. Rev. Phytopathol. 45:399-436 
9. Bliska JB. 2006. Yersinia inhibits host signaling by acetylating MAPK kinases. ACS Chem. Biol. 1:349-51

10. Bogdanove AJ. 2002. Protein-protein interactions in pathogen recognition by plants. Plant Mol. Biol. 50:981-89

11. Bogdanove AJ, Martin GB. 2000. AvrPto-dependent Pto-interacting proteins and AvrPtointeracting proteins in tomato. Proc. Natl. Acad. Sci. USA 97:8836-40

12. Bonshtien A, Lev A, Gibly A, Debbie P, Avni A, Sessa G. 2005. Molecular properties of the Xanthomonas AvrRxv effector and global transcriptional changes determined by its expression in resistant tomato plants. Mol. Plant Microbe Interact. 18:300-10

13. Boureau T, ElMaarouf-Bouteau H, Garnier A, Brisset M-N, Perino C, et al. 2006. DspA/E, a type III effector essential for Erwinia amylovora pathogenicity and growth in planta, induces cell death in host apple and nonhost tobacco plants. Mol. Plant Microbe Interact. 19:16-24

14. Bretz JR, Mock NM, Charity JC, Zeyad S, Baker CJ, Hutcheson SW. 2003. A translocated protein tyrosine phosphatase of Pseudomonas syringae pv. tomato DC3000 modulates plant defence response to infection. Mol. Microbiol. 49:389-400

15. Büttner D, Bonas U. 2002. Port of entry-the type III secretion translocon. Trends Microbiol. 10:186-92

16. Büttner D, Bonas U. 2006. Who comes first? How plant pathogenic bacteria orchestrate type III secretion. Curr. Opin. Microbiol. 9:193-200

17. Cao S, Jiang L, Song S, Jing R, Xu G. 2006. AtGRP7 is involved in the regulation of abscisic acid and stress responses in Arabidopsis. Cell. Mol. Biol. Lett. 11:526-35

18. Chinchilla D, Zipfel C, Robatzek S, Kemmerling B, Nurnberger T, et al. 2007. A flagellininduced complex of the receptor FLS2 and BAK1 initiates plant defence. Nature 448:497500

19. Chisholm ST, Coaker G, Day B, Staskawicz BJ. 2006. Host-microbe interactions: shaping the evolution of the plant immune response. Cell 124:803-14

20. Chosed R, Tomchick DR, Brautigam CA, Mukherjee S, Negi VS, et al. 2007. Structural analysis of Xanthomonas XopD provides insights into substrate specificity of ubiquitin-like protein proteases. F. Biol. Chem. 282:6773-82

21. Chung YS, Lee NR, Cheon CL, Song ES, Lee MS, et al. 2001. Molecular cloning of the nahG gene encoding salicylate hydroxylase from Pseudomonas fluorescens. Mol. Cells 11:105-9

22. Cunnac S, Wilson A, Nuwer J, Kirik A, Baranage G, Mudgett MB. 2007. A conserved carboxylesterase is a SUPPRESSOR OF AVRBST-ELICITED RESISTANCE in Arabidopsis. Plant Cell 19:688-705

23. da Cunha L, Sreerekha M-V, Mackey D. 2007. Defense suppression by virulence effectors of bacterial phytopathogens. Curr. Opin. Plant Biol. 10:349-57

24. de Torres M, Mansfield JW, Grabov N, Brown IR, Ammouneh H, et al. 2006. Pseudomonas syringae effector AvrPtoB suppresses basal defence in Arabidopsis. Plant 7. 47:368-82

25. DebRoy S, Thilmony R, Kwack YB, Nomura K, He SY. 2004. A family of conserved bacterial effectors inhibits salicylic acid-mediated basal immunity and promotes disease necrosis in plants. Proc. Natl. Acad. Sci. USA 101:9927-32

26. Desveaux D, Singer AU, Wu AJ, McNulty BC, Musselwhite L, et al. 2007. Type III effector activation via nucleotide binding, phosphorylation, and host target interaction. PLoS Pathog. $3: \mathrm{e} 48$

27. Djamei A, Pitzschke A, Nakagami H, Rajh I, Hirt H. 2007. Trojan horse strategy in Agrobacterium transformation: abusing MAPK defense signaling. Science 318:453-56

28. Dow M, Newman MA, von Roepenack E. 2000. The induction and modulation of plant defense responses by bacterial lipopolysaccharides. Annu. Rev. Phytopathol. 38:241-61 
29. Espinosa A, Alfano JR. 2004. Disabling surveillance: bacterial type III secretion system effectors that suppress innate immunity. Cell. Microbiol. 6:1027-40

30. Espinosa A, Guo M, Tam VC, Fu ZQ, Alfano JR. 2003. The Pseudomonas syringae type IIIsecreted protein HopPtoD2 possesses protein tyrosine phosphatase activity and suppresses programmed cell death in plants. Mol. Microbiol. 49:377-87

31. Felix G, Duran JD, Volko S, Boller T. 1999. Plants have a sensitive perception system for the most conserved domain of bacterial flagellin. Plant 7. 18:265-76

32. Felle H. 1998. The apoplastic $\mathrm{pH}$ of the Zea mays root cortex as measured with $\mathrm{pH}$-sensitive microelectrodes: aspects of regulation. 7. Exp. Botany 49:987-95

33. Flor HH. 1942. Inheritance of pathogenicity in Melampsora lini. Phytopathology 32:653-69

34. Fu ZQ, Guo M, Jeong B-R, Tian F, Elthon TE, et al. 2007. A type III effector ADPribosylates RNA-binding proteins and quells plant immunity. Nature 447:284-88

35. Fujikawa T, Ishihara H, Leach JE, Tsuyumu S. 2006. Suppression of defense response in plants by the avrBs3/pthA gene family of Xanthomonas spp. Mol. Plant Microbe Interact. 19:342-49

35a. Goel AK, Lundberg D, Torres MA, Matthews R, Akimoto-Tomiyama C, et al. 2008. The Pseudomonas syringae type III effector HopAM1 enhances virulence on water-stressed plants. Mol. Plant-Microbe Interact. 21:361-70

36. Gomez-Gomez L, Boller T. 2000. FLS2: an LRR receptor-like kinase involved in the perception of the bacterial elicitor flagellin in Arabidopsis. Mol. Cell 5:1003-11

37. Grant SR, Fisher EJ, Chang JH, Mole BM, Dangl JL. 2006. Subterfuge and manipulation: type III effector proteins of phytopathogenic bacteria. Annu. Rev. Microbiol. 60:425-49

38. Gürlebeck D, Thieme F, Bonas U. 2006. Type III effector proteins from the plant pathogen Xanthomonas and their role in the interaction with the host plant. F. Plant Physiol. 163:233-55

39. Gust AA, Biswas R, Lenz HD, Rauhut T, Ranf S, et al. 2007. Bacteria-derived peptidoglycans constitute pathogen-associated molecular patterns triggering innate immunity in Arabidopsis. 7. Biol. Chem. 282:32338-48

40. Ham JH, Kim MG, Lee SY, Mackey D. 2007. Layered basal defenses underlie nonhost resistance of Arabidopsis to Pseudomonas syringae pv. phaseolicola. Plant 7. 51:604-16

41. Ham JH, Majerczak DR, Arroyo-Rodriguez AS, Mackey DM, Coplin DL. 2006. WtsE, an AvrE-family effector protein from Pantoea stewartii subsp. stewartii, causes disease-associated cell death in corn and requires a chaperone protein for stability. Mol. Plant Microbe Interact. 19:1092-102

42. Hann DR, Rathjen JP. 2007. Early events in the pathogenicity of Pseudomonas syringae on Nicotiana benthamiana. Plant 7. 49:607-18

43. Hauck P, Thilmony R, He SY. 2003. A Pseudomonas syringae type III effector suppresses cell wall-based extracellular defense in susceptible Arabidopsis plants. Proc. Natl. Acad. Sci. USA 100:8577-82

44. He P, Chintamanani S, Chen Z, Zhu L, Kunkel BN, et al. 2004. Activation of a COI1dependent pathway in Arabidopsis by Pseudomonas syringae type III effectors and coronatine. Plant 7. 37:589-602

45. He P, Shan L, Lin NC, Martin GB, Kemmerling B, et al. 2006. Specific bacterial suppressors of MAMP signaling upstream of MAPKKK in Arabidopsis innate immunity. Cell 125:563-75

46. Heintzen C, Nater M, Apel K, Staiger D. 1997. AtGRP7, a nuclear RNA-binding protein as a component of a circadian-regulated negative feedback loop in Arabidopsis thaliana. Proc. Natl. Acad. Sci. USA 94:8515-20

47. Hotson A, Chosed R, Shu H, Orth K, Mudgett MB. 2003. Xanthomonas type III effector XopD targets SUMO-conjugated proteins in planta. Mol. Microbiol. 50:377-89 
48. Hotson A, Mudgett MB. 2004. Cysteine proteases in phytopathogenic bacteria: identification of plant targets and activation of innate immunity. Curr. Opin. Plant Biol. 7:384-90

49. Hückelhoven R. 2007. Cell wall-associated mechanisms of disease resistance and susceptibility. Annu. Rev. Phytopatbol. 45:101-27

50. Jamir Y, Guo M, Oh HS, Petnicki-Ocwieja T, Chen S, et al. 2004. Identification of Pseudomonas syringae type III effectors that can suppress programmed cell death in plants and yeast. Plant 7. 37:554-65

51. Janjusevic R, Abramovitch RB, Martin GB, Stebbins CE. 2006. A bacterial inhibitor of host programmed cell death defenses is an E3 ubiquitin ligase. Science 311:222-26

52. Jha G, Rajeshwari R, Sonti RV.2007. Functional interplay between two Xanthomonas oryzae pv., oryzae secretion systems in modulating virulence on rice. Mol. Plant Microbe Interact. 20:31-40

53. Jin Q, Thilmony R, Zwiesler-Vollick J, He SY. 2003. Type III protein secretion in Pseudomonas syringae. Microbes Infect. 5:301-10

54. Jones JDG, Dangl JL. 2006. The plant immune system. Nature 444:323-29

55. Kaku H, Nishizawa Y, Ishii-Minami N, Akimoto-Tomiyama C, Dohmae N, et al. 2006. Plant cells recognize chitin fragments for defense signaling through a plasma membrane receptor. Proc. Natl. Acad. Sci. USA 103:11086-91

56. Kalde M, Nuhse TS, Findlay K, Peck SC. 2007. The syntaxin SYP132 contributes to plant resistance against bacteria and secretion of pathogenesis-related protein 1. Proc. Natl. Acad. Sci. USA 104:11850-55

57. Katiyar-Agarwal S, Morgan R, Dahlbeck D, Borsani O, Villegas A Jr, et al. 2006. A pathogen-inducible endogenous siRNA in plant immunity. Proc. Natl. Acad. Sci. USA 103:18002-7

58. Kay S, Hahn S, Marois E, Hause G, Bonas U. 2007. A bacterial effector acts as a plant transcription factor and induces a cell size regulator. Science 318:648-51

59. Kim H-S, Desveaux D, Singer AU, Patel P, Sondek J, Dangl JL. 2005. The Pseudomonas syringae effector AvrRpt2 cleaves its C-terminally acylated target, RIN4, from Arabidopsis membranes to block RPM1 activation. Proc. Natl. Acad. Sci. USA 102:6496-501

60. Kim MG, da Cunha L, McFall AJ, Belkhadir Y, DebRoy S, et al. 2005. Two Pseudomonas syringae type III effectors inhibit RIN4-regulated basal defense in Arabidopsis. Cell 121:749_ 59

61. Kim YJ, Lin N-C, Martin GB. 2002. Two distinct Pseudomonas effector proteins interact with the Pto kinase and activate plant immunity. Cell 109:589-98

61a. Kniskern JM, Traw MB, Bergelson J. 2007. Salicylic acid and jasmonic acid signaling defense pathways reduce natural bacterial diversity on Arabidopsis thaliana. Mol. Plant-Microbe Interact. 20:1512-22

62. Lakatos L, Csorba T, Pantaleo V, Chapman EJ, Carrington JC, et al. 2006. Small RNA binding is a common strategy to suppress RNA silencing by several viral suppressors. EMBO 7. $25: 2768-80$

63. Lavie M, Shillington E, Eguiluz C, Grimsley N, Boucher C. 2002. PopP1, a new member of the YopJ/AvrRxv family of type III effector proteins, acts as a host-specificity factor and modulates aggressiveness of Ralstonia solanacearum. Mol. Plant Microbe Interact. 15:1058-68

63a. Lee SW, Han SW, Bartley LE, Ronald PC. 2006. From the Academy: colloquium review. Unique characteristics of Xanthomonas oryzae pv. oryzae AvrXa21 and implications for plant innate immunity. Proc. Natl. Acad. Sci. USA 103:18395-400

63b. Lemichez E, Wu Y, Sanchez J-P, Mettouchi A, Mathur J, Chua N-H. 2001. Inactivation of AtRac1 by abscisic acid is essential for stomatal closure. Genes Dev 15:1808-16 
63c. Lewis JD, Abada W, Ma W, Guttman DS, Desveaux D. 2008. The HopZ family of Pseudomonas syringae type III effectors require myristoylation for virulence and avirulence functions in Arabidopsis. F. Bacteriol. JB.01702-7

64. Li X, Lin H, Zhang W, Zou Y, Zhang J, et al. 2005. Flagellin induces innate immunity in nonhost interactions that is suppressed by Pseudomonas syringae effectors. Proc. Natl. Acad. Sci. USA 102:12990-95

65. Libault M, Wan J, Czechowski T, Udvardi M, Stacey G. 2007. Identification of 118 Arabidopsis transcription factor and 30 ubiquitin-ligase genes responding to chitin, a plantdefense elicitor. Mol. Plant Microbe Interact. 20:900-11

65a. Lin NC, Abramovitch RB, Kim YJ, Martin GB. 2006. Diverse AvrPtoB homologs from several Pseudomonas syringae pathovars elicit Pto-dependent resistance and have similar virulence activities. Appl. Environ. Microbiol. 72:702-12

66. Lindbo JA, Dougherty WG. 2005. Plant pathology and RNAi: a brief history. Annu. Rev. Phytopathol. 43:191-204

67. Lindeberg M, Cartinhour S, Myers CR, Schechter LM, Schneider DJ, Collmer A. 2006. Closing the circle on the discovery of genes encoding Hrp regulon members and type III secretion system effectors in the genomes of three model Pseudomonas syringae strains. Mol. Plant Microbe Interact. 19:1151-58

68. Loake G, Grant M. 2007. Salicylic acid in plant defence-the players and protagonists. Curr. Opin. Plant Biol. 10:466-72

69. Lopez-Solanilla E, Bronstein PA, Schneider AR, Collmer A. 2004. HopPtoN is a Pseudomonas syringae Hrp (type III secretion system) cysteine protease effector that suppresses pathogen-induced necrosis associated with both compatible and incompatible plant interactions. Mol. Microbiol. 54:353-65

70. Lu M, Tang X, Zhou JM. 2001. Arabidopsis NHO1 is required for general resistance against Pseudomonas bacteria. Plant Cell 13:437-47

71. Mackey D, Holt BF, Wiig A, Dangl JL. 2002. RIN4 interacts with Pseudomonas syringae type III effector molecules and is required for RPM1-mediated resistance in Arabidopsis. Cell 108:743-54

72. Melotto M, Underwood W, Koczan J, Nomura K, He SY. 2006. Plant stomata function in innate immunity against bacterial invasion. Cell 126:969-80

73. Meng X, Bonasera JM, Kim JF, Nissinen RM, Beer SV. 2006. Apple proteins that interact with DspA/E, a pathogenicity effector of Erwinia amylovora, the fire blight pathogen. Mol. Plant Microbe Interact. 19:53-61

74. Meszaros T, Helfer A, Hatzimasoura E, Magyar Z, Serazetdinova L, et al. 2006. The Arabidopsis MAP kinase kinase MKK1 participates in defence responses to the bacterial elicitor flagellin. Plant 7. 48:485-98

75. Miura K, Jin JB, Hasegawa PM. 2007. Sumoylation, a post-translational regulatory process in plants. Curr. Opin. Plant Biol. 10:495-502

75a. Miya A, Albert P, Shinya T, Desaki Y, Ichimura K, et al. 2007. CERK1, a LysM receptor kinase, is essential for chitin elicitor signaling in Arabidopsis. Proc. Natl. Acad. Sci. USA 104:19613-18

76. Navarro L, Dunoyer P, Jay F, Arnold B, Dharmasiri N, et al. 2006. A plant miRNA contributes to antibacterial resistance by repressing auxin signaling. Science 312:436-39

77. Nimchuk ZL, Fisher EJ, Desveaux D, Chang JH, Dangl JL. 2007. The HopX (AvrPphE) family of Pseudomonas syringae type III effectors require a catalytic triad and a novel Nterminal domain for function. Mol. Plant Microbe Interact. 20:346-57

78. Nomura K, Debroy S, Lee YH, Pumplin N, Jones J, He SY. 2006. A bacterial virulence protein suppresses host innate immunity to cause plant disease. Science 313:220-23 
79. O'Connell RJ, Panstruga R. 2006. Tête à tête inside a plant cell: establishing compatibility between plants and biotrophic fungi and oomycetes. New Phytol. 171:699-718

80. Oh H-S, Kvitko BH, Morello JE, Collmer A. 2007. Pseudomonas syringae lytic transglycosylases coregulated with the type III secretion system contribute to the translocation of effector proteins into plant cells. F. Bacteriol. 189:8277-89

81. Oh HS, Collmer A. 2005. Basal resistance against bacteria in Nicotiana benthamiana leaves is accompanied by reduced vascular staining and suppressed by multiple Pseudomonas syringae type III secretion system effector proteins. Plant 7. 44:348-59

82. Ong LE, Innes RW. 2006. AvrB mutants lose both virulence and avirulence activities on soybean and Arabidopsis. Mol. Microbiol. 60:951-62

83. Pfund C, Tans-Kersten J, Dunning FM, Alonso JM, Ecker JR, et al. 2004. Flagellin is not a major defense elicitor in Ralstonia solanacearum cells or extracts applied to Arabidopsis thaliana. Mol. Plant Microbe Interact. 17:696-706

83a. Rentel MC, Leonelli L, Dahlbeck D, Zhao B, Staskawicz BJ. 2008. Recognition of the Hyaloperonospora parasitica effector ATR13 triggers resistance against oomycete, bacterial, and viral pathogens. Proc. Natl. Acad. Sci. USA 105:1091-96

84. Ridout CJ, Skamnioti P, Porritt O, Sacristan S, Jones JDG, Brown JKM. 2006. Multiple avirulence paralogues in cereal powdery mildew fungi may contribute to parasite fitness and defeat of plant resistance. Plant Cell 18:2402-14

85. Robatzek S, Chinchilla D, Boller T. 2006. Ligand-induced endocytosis of the pattern recognition receptor FLS2 in Arabidopsis. Genes Dev. 20:537-42

86. Roden J, Eardley L, Hotson A, Cao Y, Mudgett MB. 2004. Characterization of the Xanthomonas AvrXv4 effector, a SUMO protease translocated into plant cells. Mol. Plant Microbe Interact. 17:633-43

87. Ron M, Avni A. 2004. The receptor for the fungal elicitor ethylene-inducing xylanase is a member of a resistance-like gene family in tomato. Plant Cell 16:1604-15

88. Rooney HCE, van't Klooster JW, van der Hoorn RAL, Joosten MHAJ, Jones JDG, de Wit PJGM. 2005. Cladosporium Avr2 inhibits tomato Rcr3 protease required for Cf-2-dependent disease resistance. Science 308:1783-86

89. Rose JKC, Ham K-S, Darvill AG, Albersheim P. 2002. Molecular cloning and characterization of glucanase inhibitor proteins: coevolution of a counterdefense mechanism by plant pathogens. Plant Cell 14:1329-45

90. Rosebrock TR, Zeng L, Brady JJ, Abramovitch RB, Xiao F, Martin GB. 2007. A bacterial E3 ubiquitin ligase targets a host protein kinase to disrupt plant immunity. Nature 448:370-74

91. Sarmiento C, Gomez E, Meier M, Kavanagh TA, Truve E. 2007. Cocksfoot mottle virus P1 suppresses RNA silencing in Nicotiana benthamiana and Nicotiana tabacum. Virus Res. 123:95-99

92. Schechter LM, Vencato M, Jordan KL, Schneider SE, Schneider DJ, Collmer A. 2006. Multiple approaches to a complete inventory of Pseudomonas syringae pv. tomato DC3000 type III secretion system effector proteins. Mol. Plant Microbe Interact. 19:1180-92

93. Shan L, He P, Sheen J. 2007. Intercepting host MAPK signaling cascades by bacterial type III effectors. Cell Host Microbe 1:167-74

94. Shimada C, Lipka V, O'Connell R, Okuno T, Schulze-Lefert P, Takano Y. 2006. Nonhost resistance in Arabidopsis-Colletotrichum interactions acts at the cell periphery and requires actin filament function. Mol. Plant Microbe Interact. 19:270-79

95. Shipton PJ. 1977. Monoculture and soilborne plant pathogens. Annu. Rev. Phytopathol. 15:387-407

96. Silverstein KA, Graham MA, Paape TD, VandenBosch KA. 2005. Genome organization of more than 300 defensin-like genes in Arabidopsis. Plant Physiol. 138:600-10 
96a. Sohn KH, Lei R, Nemri A, Jones JD. 2007. The downy mildew effector proteins ATR1 and ATR13 promote disease susceptibility in Arabidopsis thaliana. Plant Cell 19:4077-90

97. Suarez-Rodriguez MC, Adams-Phillips L, Liu Y, Wang H, Su S-H, et al. 2007. MEKK1 is required for flg22-induced MPK4 activation in Arabidopsis plants. Plant Physiol. 143:661-69

98. Sun W, Dunning FM, Pfund C, Weingarten R, Bent AF. 2006. Within-species flagellin polymorphism in Xanthomonas campestris pv campestris and its impact on elicitation of Arabidopsis FLAGELLIN SENSING2-dependent defenses. Plant Cell 18:764-79

99. Sundin GW. 2007. Genomic insights into the contribution of phytopathogenic bacterial plasmids to the evolutionary history of their hosts. Annu. Rev. Phytopathol. 45:129-51

100. Swords KM, Dahlbeck D, Kearney B, Roy M, Staskawicz BJ. 1996. Spontaneous and induced mutations in a single open reading frame alter both virulence and avirulence in Xanthomonas campestris pv. vesicatoria avrBs2. F. Bacteriol. 178:4661-69

101. Szurek B, Rossier O, Hause G, Bonas U. 2002. Type III-dependent translocation of the Xanthomonas AvrBs3 protein into the plant cell. Mol. Microbiol. 46:13-23

102. Taguchi F, Shimizu R, Inagaki Y, Toyoda K, Shiraishi T, Ichinose Y. 2003. Post-translational modification of flagellin determines the specificity of HR induction. Plant Cell Physiol. 44:342-49

103. Tellström V, Usadel B, Thimm O, Stitt M, Kuster H, Niehaus K. 2007. The lipopolysaccharide of Sinorbizobium meliloti suppresses defense-associated gene expression in cell cultures of the host plant Medicago truncatula. Plant Physiol. 143:825-37

103a. Thines B, Katsir L, Melotto M, Niu Y, Mandaokar A, et al. 2007. JAZ repressor proteins are targets of the SCFCOI1 complex during jasmonate signalling. Nature 448:661-65

104. Tian M, Benedetti B, Kamoun S. 2005. A second Kazal-like protease inhibitor from Phytophthora infestans inhibits and interacts with the apoplastic pathogenesis-related protease P69B of tomato. Plant Physiol. 138:1785-93

105. Tian M, Win J, Song J, van der Hoorn R, van der Knaap E, Kamoun S. 2007. A Phytophthora infestans cystatin-like protein targets a novel tomato papain-like apoplastic protease. Plant Physiol. 143:364-77

106. Underwood W, Melotto M, He SY. 2007. Role of plant stomata in bacterial invasion. Cell Microbiol. 9:1621-22

107. Underwood W, Zhang S, He SY. 2007. The Pseudomonas syringae type III effector tyrosine phosphatase HopAO1 suppresses innate immunity in Arabidopsis thaliana. Plant 7. 52:658-72

108. van den Burg HA, Harrison SJ, Joosten MH, Vervoort J, de Wit PJ. 2006. Cladosporium fulvum Avr4 protects fungal cell walls against hydrolysis by plant chitinases accumulating during infection. Mol. Plant Microbe Interact. 19:1420-30

109. Van Der Biezen EA, Jones JDG. 1998. Plant disease-resistance proteins and the gene-forgene concept. Trends Biochem. Sci. 23:454-56

110. van Loon LC, Rep M, Pieterse CMJ. 2006. Significance of inducible defense-related proteins in infected plants. Annu. Rev. Phytopathol. 44:135-62

111. Vinatzer BA, Teitzel GM, Lee M-W, Jelenska J, Hotton S, et al. 2006. The type III effector repertoire of Pseudomonas syringae pv. syringae $\mathrm{B} 728 \mathrm{a}$ and its role in survival and disease on host and nonhost plants. Mol. Microbiol. 62:26-44

112. Vorwerk S, Somerville S, Somerville C. 2004. The role of plant cell wall polysaccharide composition in disease resistance. Trends Plant Sci. 9:203-9

113. Wang M-B, Metzlaff M. 2005. RNA silencing and antiviral defense in plants. Curr. Opin. Plant Biol. 8:216-22

114. Wei C-F, Kvitko BH, Shimizu R, Crabill E, Alfano JR, et al. 2007. A Pseudomonas syringae pv. tomato DC3000 mutant lacking the type III effector HopQ1-1 is able to cause disease in the model plant Nicotiana benthamiana. Plant 7. 51:32-46 
114a. Win J, Morgan W, Bos J, Krasileva KV, Cano LM, et al. 2007. Adaptive evolution has targeted the C-terminal domain of the RXLR effectors of plant pathogenic oomycetes. Plant Cell 19:2349-69

114b. Xiang T, Zong N, Zou Y, Wu Y, Zhang J, et al. 2008. Pseudomonas syringae effector AvrPto blocks innate immunity by targeting receptor kinases. Curr. Biol. 18:74-80

115. Zeng L-R, Vega-Sanchez ME, Zhu T, Wang G-L. 2006. Ubiquitination-mediated protein degradation and modification: an emerging theme in plant-microbe interactions. Cell Res. 16:413-26

116. Zhang J, Shao F, Li Y, Cui H, Chen L, et al. 2007. A Pseudomonas syringae effector inactivates MAPKs to suppress PAMP-induced immunity in plants. Cell Host Microbe 1:175-85

117. Zipfel C, Kunze G, Chinchilla D, Caniard A, Jones JDG, et al. 2006. Perception of the bacterial PAMP EF-Tu by the receptor EFR restricts Agrobacterium-mediated transformation. Cell 125:749-60

118. Zipfel C, Robatzek S, Navarro L, Oakeley EJ, Jones JDG, et al. 2004. Bacterial disease resistance in Arabidopsis through flagellin perception. Nature 428:764-67 


\section{Contents}

The Phenotypic Expression of a Genotype: Bringing Muddy Boots and Micropipettes Together

Roger Hull

The Origin of Ceratocystis fagacearum, the Oak Wilt Fungus

Fennifer Fuzwik, Thomas C. Harrington, William L. MacDonald, and David N. Appel

The Powdery Mildews: A Review of The World's Most Familiar (Yet Poorly Known) Plant Pathogens

Dean A. Glawe

Plants as a Habitat for Beneficial and/or Human Pathogenic Bacteria

Heather L. L. Tyler and Eric W. Triplett

The Origins of Plant Pathogens in Agro-Ecosystems

Eva H. Stukenbrock and Bruce A. McDonald

Role of Stomata in Plant Innate Immunity and Foliar Bacterial Diseases

Maeli Melotto, William Underwood, and Sheng-Yang He

Models of Fungicide Resistance Dynamics

Frank van den Bosch and Christopher A. Gilligan

Siderophores in Fungal Physiology and Virulence

Hubertus Haas, Martin Eisendle, and Gillian Turgeon

Breaking the Barriers: Microbial Effector Molecules Subvert

Plant Immunity

Vera Göbre and Silke Robatzek

Yeast as a Model Host to Explore Plant Virus-Host Interactions

Peter D. Nagy

Living in Two Worlds: The Plant and Insect Lifestyles

of Xylella fastidiosa

Subhadeep Chatterjee, Rodrigo P.P. Almeida, and Steven Lindow. 
Identification and Rational Design of Novel Antimicrobial Peptides for Plant Protection Fose F. Marcos, Alberto Muñoz, Enrique Pérez-Payá, Santosh Misra, and Belén López-García

Direct and Indirect Roles of Viral Suppressors of RNA Silencing in Pathogenesis Juan A. Díaz-Pendón and Shou-Wei Ding.

Insect Vector Interactions with Persistently Transmitted Viruses

Saskia A. Hogenhout, El-Desouky Ammar, Anna E. Whitfield, and Margaret G. Redinbaugh

Plant Viruses as Biotemplates for Materials and Their Use in Nanotechnology Mark Young, Debbie Willits, Masaki Ucbida, and Trevor Douglas 361

Epidemiological Models for Invasion and Persistence of Pathogens Christopher A. Gilligan and Frank van den Bosch... 385

\section{Errata}

An online log of corrections to Annual Review of Phytopathology articles may be found at http://phyto.annualreviews.org/ 